\title{
ARTICLE OPEN Mutual dependency between lncRNA LETN and protein NPM1 in controlling the nucleolar structure and functions sustaining cell proliferation
}

\author{
Xianteng Wang ${ }^{1,2,3}$, Xiaolin $\mathrm{Hu}^{1,2,3,4}$, Wanlu Song ${ }^{1,2,3}$, Hui Xu ${ }^{1,2,3}$, Zhengtao Xiao ${ }^{1,2,3}$, Rongyao Huang ${ }^{1,2,3}$, Qingran Bai ${ }^{5}$, Fan Zhang ${ }^{1,2,3}$, \\ Yongzhen Chen ${ }^{1,2,3}$, Yu Liu ${ }^{1,2,3}$, Jianhuo Fang ${ }^{1,2,3}$, Xin $\mathrm{Li}^{1,2,3}$, Qin Shen ${ }^{5}$, Haitao Zhao ${ }^{6}$ and Xuerui Yang (iD ${ }^{1,2,3}$
}

Fundamental processes such as ribosomal RNA synthesis and chromatin remodeling take place in the nucleolus, which is hyperactive in fast-proliferating cells. The sophisticated regulatory mechanism underlying the dynamic nucleolar structure and functions is yet to be fully explored. The present study uncovers the mutual functional dependency between a previously uncharacterized human long non-coding RNA, which we renamed LETN, and a key nucleolar protein, NPM1. Specifically, being upregulated in multiple types of cancer, LETN resides in the nucleolus via direct binding with NPM1. LETN plays a critical role in facilitating the formation of NPM1 pentamers, which are essential building blocks of the nucleolar granular component and control the nucleolar functions. Repression of LETN or NPM1 led to similar and profound changes of the nucleolar morphology and arrest of the nucleolar functions, which led to proliferation inhibition of human cancer cells and neural progenitor cells. Interestingly, this inter-dependency between LETN and NPM1 is associated with the evolutionarily new variations of NPM1 and the coincidental emergence of LETN in higher primates. We propose that this human-specific protein-IncRNA axis renders an additional yet critical layer of regulation with high physiological relevance in both cancerous and normal developmental processes that require hyperactive nucleoli.

Cell Research (2021) 31:664-683; https://doi.org/10.1038/s41422-020-00458-6

\section{INTRODUCTION}

Comprehensive annotations of transcriptomes have revealed a vast number of long non-coding RNAs (IncRNAs) in various species. ${ }^{1-5}$ For the past years, extensive studies have uncovered hundreds of IncRNAs in human cells with various molecular and cellular functions. ${ }^{6,7}$ Specifically, many of these IncRNAs have been emerging as fine-tuners of key pathways related to a variety of processes, such as development ${ }^{5}$ and complex diseases such as cancer. ${ }^{8-10}$ Among them, physiologically relevant IncRNAs with fundamental and indispensable functions are still rare.

The nucleolus is a non-membrane-bound subnuclear compartment, which is a crucial organelle for fundamental processes such as rDNA transcription and ribosome biogenesis. ${ }^{11}$ Dysregulation of the nucleolar organization and functions thereby results in a multitude of cellular and physiological disorders, such as ribosomopathies, aging, and cancer. ${ }^{12,13}$ The major function of the nucleolus, rDNA transcription by polymerase I (Pol I), is subjected to complicated regulation, which involves several recently discovered IncRNAs in human cells, including PAPAS, ${ }^{14,15}$ SLERT, ${ }^{16}$ and HOXB-AS3. ${ }^{17}$ These IncRNAs function mainly on the Pol I-mediated rDNA transcription machinery rather than on the nucleolus itself. In the present study, we identified a IncRNA (transcript ID: ENST00000564237.1, gene name: RP11-196G18.22) that directly controls the structural organization and major functions of the nucleolus via a key nucleolar protein NPM1 (also named B23 or nucleophosmin).

Known as an essential and the most abundant protein in the nucleolus, ${ }^{18-20}$ NPM1 is localized in the granular component (GC) and controls the structured formation of the nucleolus. ${ }^{20-23}$ NPM1 is a well-characterized multifunctional protein that plays key roles in rDNA transcription in the nucleolus, 19,20,24 nucleosome assembly as a histone chaperone protein, ${ }^{25,26}$ and ribosome biogenesis by shuffling ribosomal proteins. ${ }^{27,28}$ Due to its critical position in multiple biological processes, NPM1 has been shown to be essential for embryogenesis ${ }^{29}$ and tumorigenesis. ${ }^{30,31}$

The expression of IncRNA RP11-196G18.22 is relatively low in most human adult normal tissues but elevated in multiple types of tumors and in embryonic tissues ${ }^{32}$ (Supplementary information, Fig. S1a). The molecular function of the IncRNA RP11-196G18.22 has not yet been studied. Here, we show that the major functions of NPM1, such as promoting rRNA synthesis and chromatin condensation, all depend on the IncRNA RP11-196G18.22. Specifically, by directly binding with NPM1, the IncRNA is concentrated in the nucleolus and plays a critical role for the formation of NPM1 oligomers, which are main building blocks of the GC of the nucleolus and required for the functional activities of

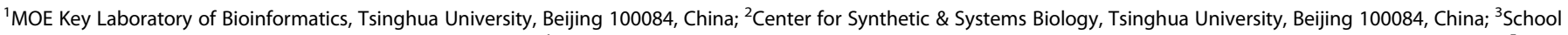

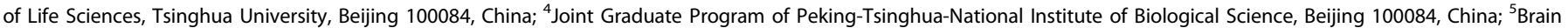

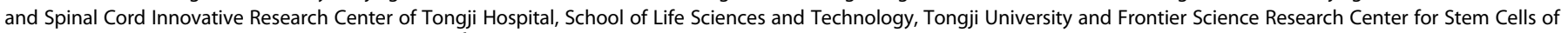

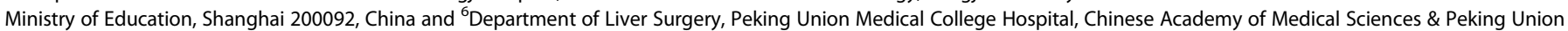
Medical College (CAMS \& PUMC), Beijing 100730, China

Correspondence: Xuerui Yang (yangxuerui@tsinghua.edu.cn)

Received: 18 June 2020 Accepted: 30 November 2020

Published online: 11 January 2021 
NPM1. ${ }^{20,22,33-37}$ Indeed, repression of the IncRNA RP11-196G18.22 generated phenotypes identical to those observed with NPM1 knockdown, i.e., disordered morphology and functions of the nucleolus and strong inhibition of proliferation of human cancer cells and neuronal progenitor cells (NPCs). We therefore propose to rename the IncRNA RP11-196G18.22 as LETN (IncRNA essential for tumor cell proliferation via NPM1).

In summary, we have uncovered the mutual functional dependency between the key multi-functional protein NPM1 and a previously uncharacterized IncRNA. Interestingly, our comparative genomic analyses further showed that this interdependency between LETN and NPM1 is associated with the evolutionarily new variations of NPM1, which are coincidental with the emergence of LETN in higher primates. Therefore, this humanspecific LETN-NPM1 axis possessed a highly critical position in the fundamental processes in the nucleolus by implementing an additional yet critical layer of regulation. This is rare to see and renders the high physiological relevance of this IncRNA in cancer and potentially neuronal development.

\section{RESULTS}

IncRNA LETN is critical for cancer cell proliferation and tumor development

The expression of IncRNA LETN (previously named as RP11196G18.22, at chr1:149,844,498-149,849,024 of GRCh38/hg38) is relatively high in the human embryonic tissues but then largely repressed in most adult normal tissues ${ }^{32}$ (Supplementary information, Fig. S1a). The gene locus of LETN exhibits frequent copy number amplifications in liver hepatocellular carcinoma (LIHC) and many other types of cancer (Fig. 1a; Supplementary information, Fig. S1b). Consistently, RNA expression of LETN was significantly upregulated in tumors compared to their adjacent normal tissues in a broad range of cancers, including bile duct, liver, lung, and kidney (Fig. 1b).

In cancer cell lines such as HUH7 (liver cancer) and HCC827 (lung cancer), LETN has fairly high RNA copy numbers among IncRNAs (nearly 200 copies per cell, as shown by quantitative PCR with standard RNA spike-in as the reference) (Supplementary information, Fig. S2). Although the genome annotation of LETN has been available, we performed $5^{\prime}$ and $3^{\prime}$ rapid amplification of CDNA ends (RACE) to precisely identify the two ends of LETN in HUH7 cells. The $3^{\prime}$ RACE confirmed the previously annotated $3^{\prime}$ end of LETN (chr1:149,844,498), but the amplified sequence from $5^{\prime}$ RACE was 23nt shorter than the reference at the $5^{\prime}$ end (Supplementary information, Fig. S3a). Therefore, the genome annotation of LETN may be revised to chr1:149,844,498-149,849,001. However, as many of the transcription start sites are known to vary in different cell contexts, ${ }^{38,39}$ updating the genome annotation of LETN is not urgently needed. Finally, the lengths of the amplified products from $5^{\prime}$ and $3^{\prime}$ RACE have supported the annotated full length ( $\left.4.5 \mathrm{knt}\right)$ of LETN (Supplementary information, Fig. S3a), which was further confirmed by northern blots of LETN in control and LETN knockdown HUH7 cells (Supplementary information, Fig. S3b).

siRNA-mediated knockdown of LETN (Supplementary information, Fig. S4a) significantly repressed cell proliferation rates in various cancer cell lines, including HUH7, HCC827, PC3 and DU145 (prostate cancer) (Fig. 1c). Lentivirus-mediated long-term knockdown of LETN with shRNA (Supplementary information, Fig. S4b) reduced anchorage-dependent or -independent colony formation from the cells (Fig. 1d, e). Gene knockout of LETN via CRISPR-Cas9 in $\mathrm{HUH} 7$ cells $(80 \%$ reduction of $L E T N$ expression after enrichment of the cells with positive Cas9-sgRNA vector transfection, Supplementary information, Fig. S5a) also significantly reduced cell proliferation and colony formation (Supplementary information, Fig. S5b, c). Additionally, the reduction of cell proliferation rate was also confirmed by LETN knockdown mediated by antisense oligonucleotides (ASO) (Supplementary information,
Fig. S6a, b). On the other hand, lentivirus-mediated stable overexpression of LETN (approximately tenfold increase) in HUH7 cells resulted in significant increases in cell proliferation and colony formation (Fig. 1f, g).

Finally, in multiple xenograft tumor models established with cancer cell lines including HUH7 and HCC827, stable knockdown of LETN greatly inhibited tumor growth (Fig. 1h; Supplementary information, Fig. S7), whereas its overexpression in HUH7 granted significant growth advantages to the tumors (Fig. 1i). From the results above, it is clear that the IncRNA LETN plays a potent tumor-promoting role in multiple cancer cells, and even partial repression of LETN could lead to significant arrest of cell proliferation and tumor growth.

IncRNA LETN binds to and coaggregates with NPM1 in the nucleolus

RNA Fluorescence in situ hybridization (FISH) and qPCR of the cytoplasmic and nuclear fractions showed that the endogenous LETN is predominantly, if not only, localized in the cell nucleus (Supplementary information, Fig. S8a, b). Note that the siRNA transfection resulted in significant knockdown of LETN in the nucleus, as confirmed by both FISH and qPCR (Supplementary information, Fig. S8a, b). In addition, the distribution of LETN in the nucleus and the DAPI staining strongly indicated that LETN is enriched in the nucleolus (Supplementary information, Fig. S8a). This was directly confirmed by qPCR assays of LETN in the three cell fractions (cytoplasm, nucleoplasm, and nucleolus) (Fig. 2a), of which the purities were validated by qPCR assays of GAPDH, U6, and pre-rRNA, respectively (Supplementary information, Fig. S9).

Next, we used the technique of MS2 tagging followed by mass spectrometry $^{40}$ to explore the proteins that bind to LETN (schematic description of the assay provided in Supplementary information, Fig. S10a). The results showed that NPM1 was the most enriched binding partner of LETN (Fig. 2b). It is worth noting that more than half of the other proteins pulled out by the MS2tagged LETN (85 out of 152) were also found in the proteins pulled down by NPM1 immunoprecipitation (176 in total) (Supplementary information, Fig. S10b), which is a strongly significant overlap $(P$-value close to 0$)$.

On the other hand, the NPM1-RNA immunoprecipitation (RIP) assay, i.e., immunoprecipitation of the endogenous NPM1 followed by qPCR, confirmed the binding of NPM1 to LETN under both native and formaldehyde cross-linking conditions (Fig. 2c). Another series of RIP assays with multiple exogenously expressed truncated forms of NPM1 showed that the C-terminal domain of NPM1 is essential for directly binding with LETN (Supplementary information, Fig. S11a). NPM1 is one of the most abundant proteins in the nucleolus, and it is frequently used as a nucleolar marker. ${ }^{41-43}$ The nucleolar localization signal (NoLS) of NPM1 is located in the C-terminal region of NPM1. ${ }^{44}$ Therefore, as expected, the two fragments NPM1.1 and NPM1.2 failed to concentrate in the nucleolus (Supplementary information, Fig. $\mathrm{S} 11 \mathrm{~b})$, whereas the fragment NPM1.3 and the full-length NPM1 were highly enriched in the nucleoli (Supplementary information, Fig. S11b). To exclude the possibility of NPM1-LETN interaction simply due to their colocalization in the nucleoli, we performed an in vitro binding assay with biotin-labeled LETN and the fragmented and full-length NPM1 proteins. As shown in Supplementary information, Fig. S11C, the two NPM1 fragments (NPM1.1 and NPM1.2) indeed have lost the binding capacity with LETN, whereas the C-terminal fragment (NPM1.3) and the full-length NPM1 showed clear binding with LETN.

Next, to identify the NPM1-binding region in LETN, we used a series of biotin-labeled fragments of the IncRNA for protein pulldown, followed by western blotting for NPM1. The first round of fragmentation narrowed down the binding to the region of $500-2000$ nt of LETN (Supplementary information, Fig. S12a). The second round, designed for the region of $1-2000 \mathrm{nt}$ and with a 
8022 tumors from TCGA

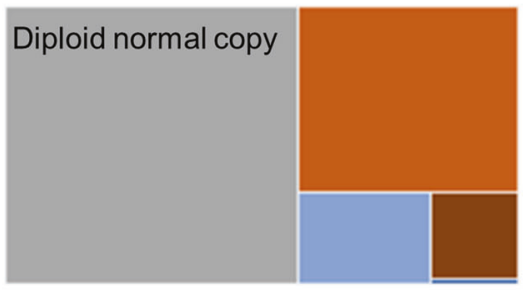

High-level amp. $\square$ Single del.

Low-level amp. Homozygous del.

\section{b}

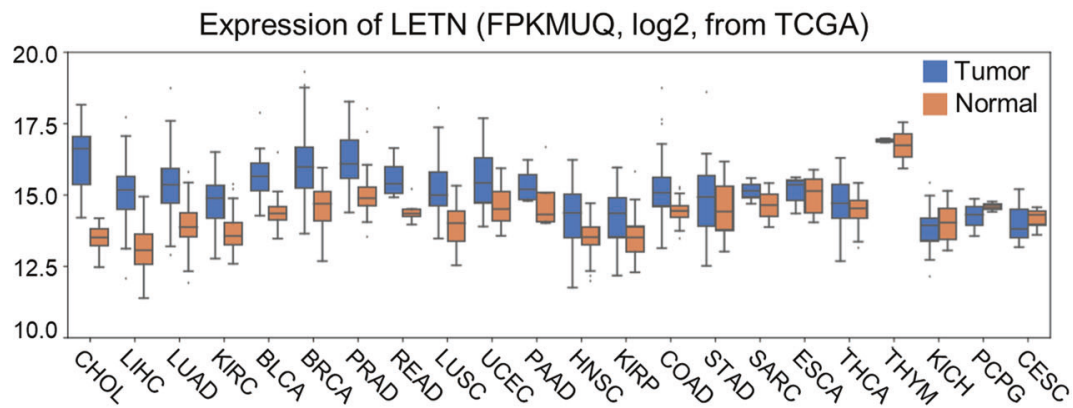

C

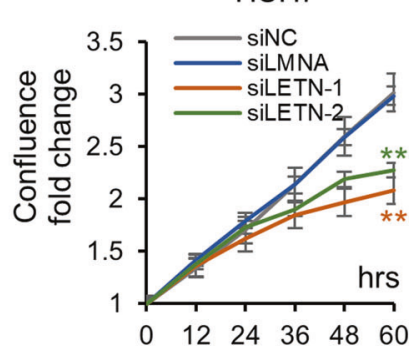

HCC827

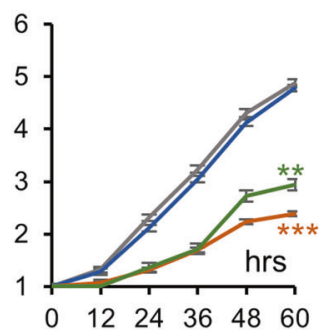

DU145

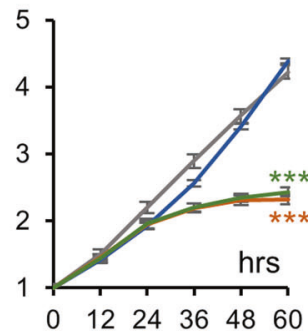

PC3

d
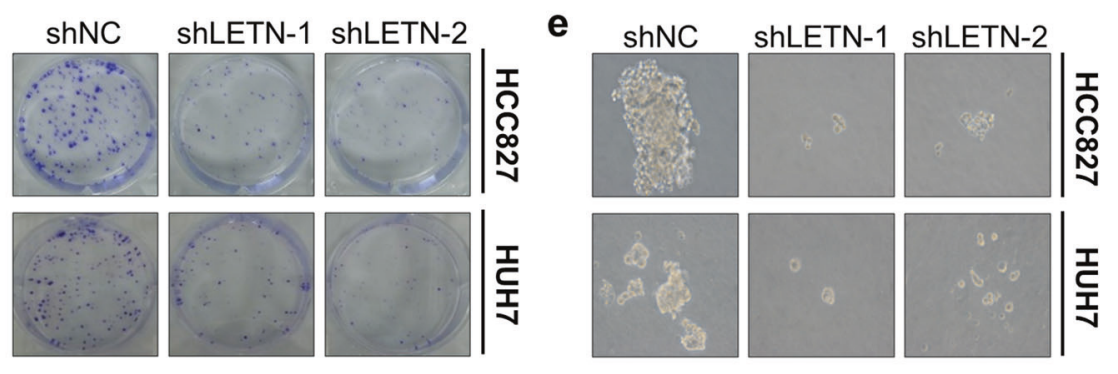

h

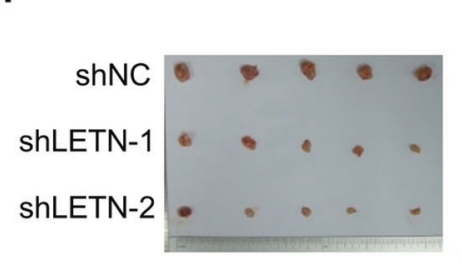

Tumor Weight (mg)
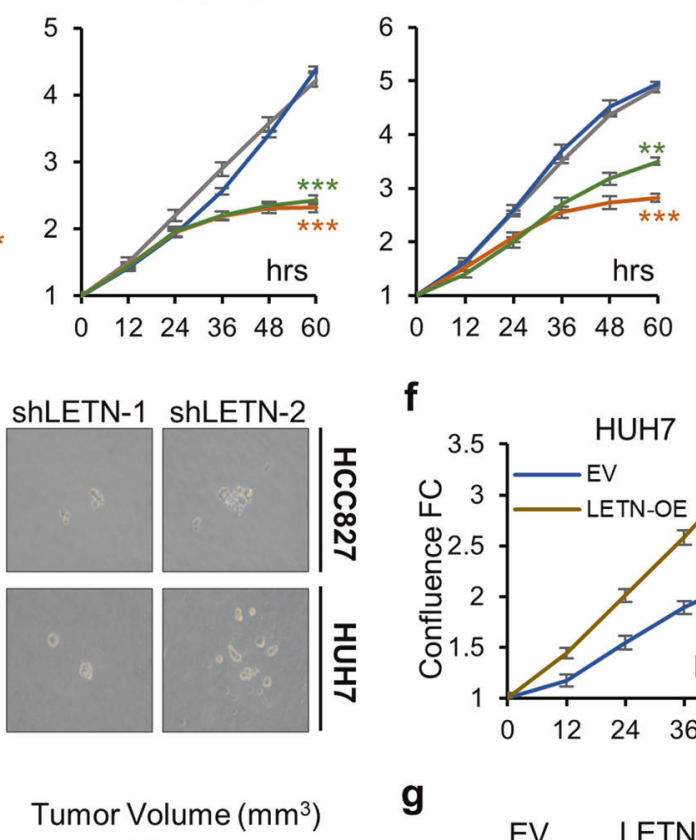

f
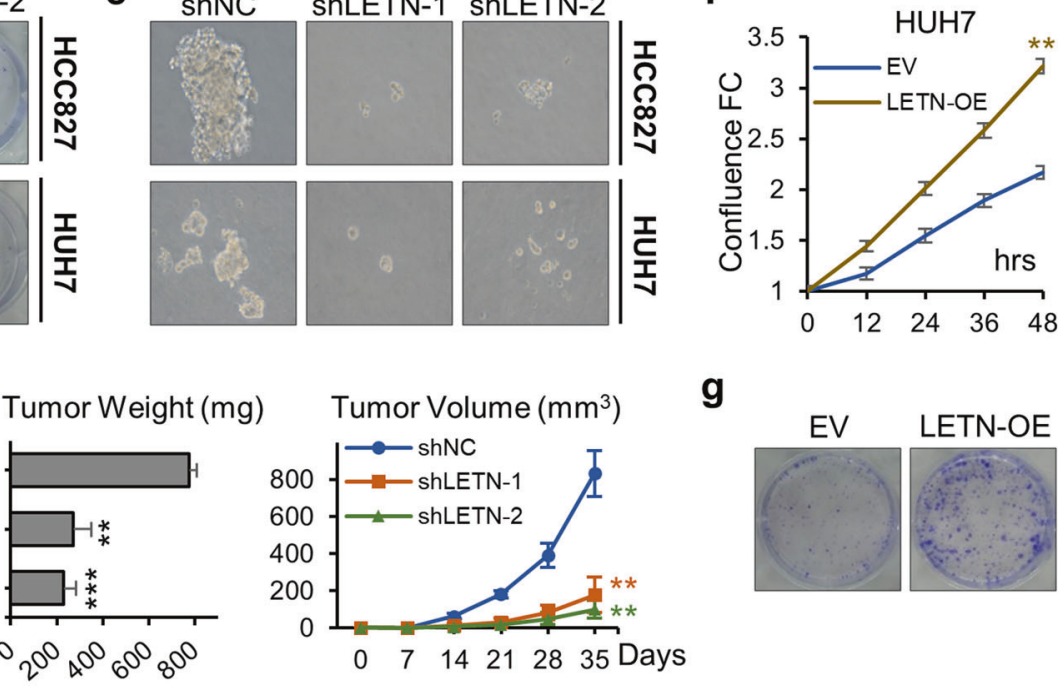

g

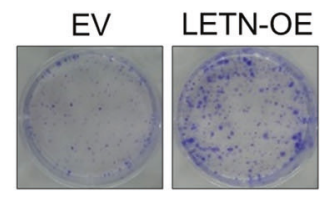

i

Tumor Weight $(\mathrm{mg}) \quad$ Tumor Volume $\left(\mathrm{mm}^{3}\right)$
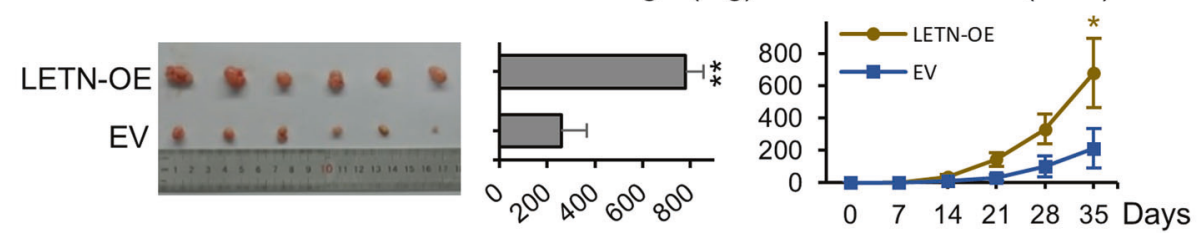

Fig. 1 Expression of LETN in cancers and its function in tumor cell proliferation. a Copy number variations of the LETN gene locus in pancancer tumors. The data were obtained from 22 cancer types in TCGA. Refer to Supplementary information, Fig. S1b for the data of each specific cancer type. b Box plots showing the RNA expression levels of LETN (FPKM after upper-quantile normalization) in tumors of different cancer types and in the corresponding normal tissues. The data were obtained from TCGA. The 22 cancer types were sorted from left to right according to the significance of the LETN differential expression between the tumors and the paired normal tissues. c Cell proliferation curves of HUH7, HCC827, DU145 and PC3 cells upon siRNA-mediated knockdown of LETN. The $y$-axis, cell confluence fold-change (FC) in relative to the confluence at time 0 . The error bars represent the \pm SD of three biological replicates. $\mathbf{d}$, e Anchorage-dependent (d) and -independent (e) colony formation of HCC827 and HUH7 cells upon shRNA-mediated knockdown of LETN. f Cell proliferation curves of HUH7 and HCC827 cells with stable overexpression of LETN. The error bars represent the \pm SD of three biological replicates. $\mathbf{g}$ Anchorage-dependent colony formation of HUH7 and HCC827 cells with stable overexpression of LETN. h, i Three million of the HUH7 cells with lentivirus-mediated stable LETN knockdown (h) or 1 million of the cells with stable overexpression of LETN (i) were implanted into the nude mice $(n=5$ for knockdown and $n=6$ for overexpression) for xenograft tumor models. Images, weights, and growth records of the tumors are being presented. The error bars represent the \pm SD of the tumors. 
a

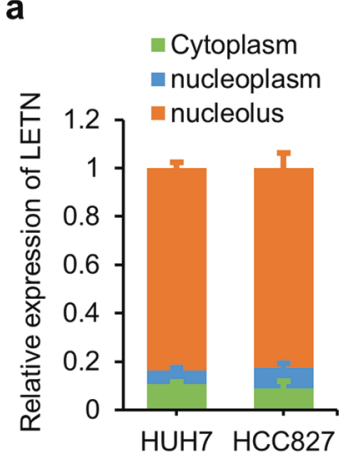

b
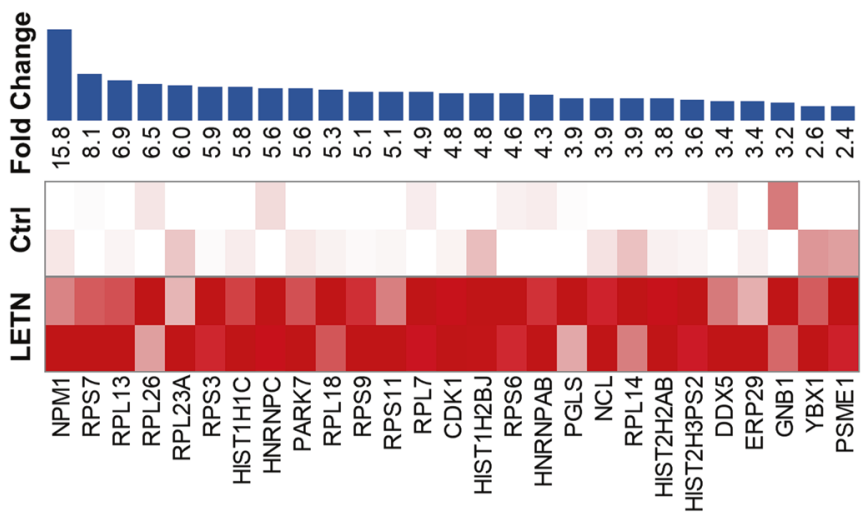

d

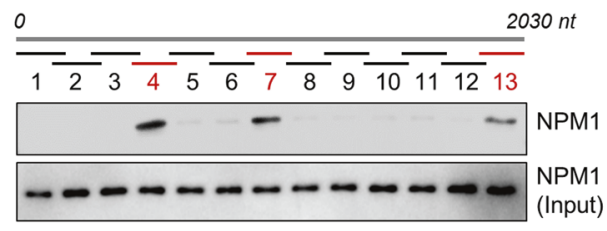

e
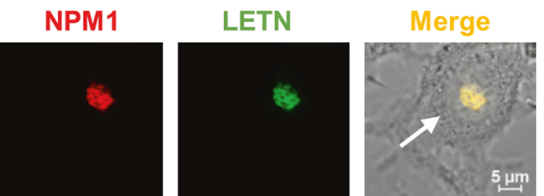

Time

(hr:min)

$2: 30$
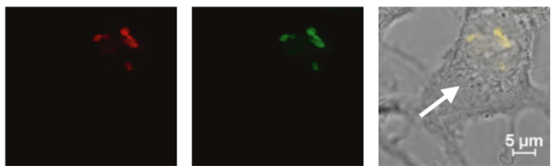

5:15
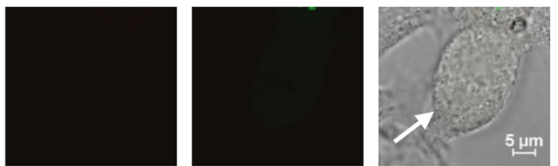

6:00
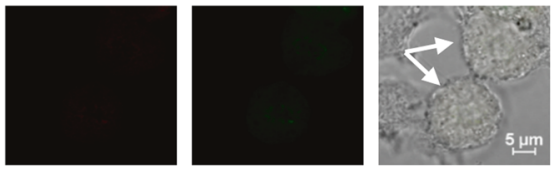

$6: 45$
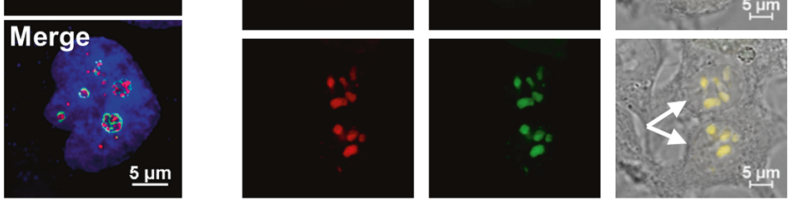

Fig. 2 Direct interaction between LETN and NPM1. a RT-qPCR of LETN in the cytoplasmic, nucleoplasmic and nucleolar fractions of HUH7 and HCC827 cells. Shown in Supplementary information, Fig. S9, GAPDH, U6 and pre-rRNA were used as markers of the three compartments, respectively. b Mass spectrometry profiles of the proteins pulled down by MS2-tagged LETN RIP in HUH7 cells, compared to the MS2-RIP negative control. For two biological replicates, all the proteins detected by mass spectrometry analysis in either LETN-MS2-RIP (LETN) or MS2RIP (ctrl) are included in the table. c qPCR of LETN and MALAT1 after native and formaldehyde cross-linking NPM1-RIP in HUH7 cells. MALAT1 was used as a negative control. The error bars represent the \pm SD of three replicates. $\mathbf{d}$ Interactions between fragmented LETN and NPM1. Thirteen biotin-labeled RNA fragments (about $180 \mathrm{nt}$ each) covering the first $2030 \mathrm{nt}$ of LETN were used for protein pull-down in HUH7 cells, followed by western blotting of NPM1. See Supplementary information, Fig. S12a, b for more data. e Representative images from time-lapse microscope of a dividing HUH7 cell, showing the mCherry-labeled NPM1 (red) and MS2-tagged LETN marked by MS2-GFP fusion protein (green). Twenty-four hours after transfections of plv-NPM1-mcherry, pMS2-GFP, and pcDNA3.1-LETN-MS2, the cells were put under a microscope and photographed every $15 \mathrm{~min}$ for up to $12.5 \mathrm{~h}$. Refer to Supplementary information, Fig. S13b and Video S1 for the full data. SIM images showing the nucleus staining by DAPI (blue), IF (red) of NPM1 (f), UBF (g), or fibrillarin (h), and MS2-tagged LETN marked by MS2-GFP (green) in the HUH7 cells after LETN knockout and re-expression with the pcDNA3.1-LETN-MS2 plasmid. Quantifications of the colocalizations between $L E T N$ and the three proteins are provided in Supplementary information, Fig. S13c.

higher resolution, further identified three NPM1 binding domains, i.e., $500-680 \mathrm{nt}$ (fragment 4), 950-1130 nt (fragment 7), and 1850-2030 nt (fragment 13) (Fig. 2d). Removing any of these three domains indeed slightly attenuated NPM1 binding, but only the simultaneous deletion of all three domains could completely block NPM1 binding (Supplementary information, Fig. S12b).

We were not able to detect any significantly conserved motifs among the three LETN fragments identified above $(4,7$, and 13$)$. 
668

We suspect that like many other IncRNAs, it is the higher order structure of the RNA that has enabled its interaction with NPM1. In addition, although the LETN fragments 4, 7, and 13 were responsible for the direct interaction with NPM1, simply expressing these three fragments together has no rescuing effect on cell proliferation after knockdown of the endogenous LETN (Supplementary information, Fig. S12c). In fact, the truncated LETN of the first $1000 \mathrm{nt}$ also showed no rescuing effect. By contrast, the first 2000 or $3000 \mathrm{nt}$ of LETN significantly rescued cell proliferation, but still not as potent as the LETN full length. Based on these observations, it is a plausible hypothesis that the full molecular and cellular functions of LETN depend on its high-order structure, instead of some short sequence motifs.

Finally, immunofluorescence staining of endogenous NPM1 further showed its clear coaggregation and colocalization with LETN in the nucleoli (Supplementary information, Fig. S13a). In fact, taking one field of the time-lapse microscopy as an example, the exogenously expressed NPM1 and LETN exhibited perfectly synchronized and colocalized dissociation and aggregation in the nucleus before and after cell division (Fig. 2e; Supplementary information, Fig. S13b and Video S1). More examples of the timelapse microscopy images are provided in Supplementary information, Videos S2-5. NPM1 is predominantly localized in the GC compartment of the nucleolus. ${ }^{11,22,45}$ High-resolution IF of the endogenous NPM1 and RNA FISH of LETN with structured illumination microscopy (SIM) illustrated colocalization of LETN and NPM1 mostly in the peripheral regions of the nucleolus (Fig. 2f), apparently the GC. This strong colocalization was nicely supported by the Pearson's correlation coefficients $(P C C)^{46}$ between the distributions of the two factors in multiple cells (Supplementary information, Fig. S13C). On the other hand, UBF as a marker of the nucleolus fibrillar center (FC) ${ }^{45,47}$ and fibrillarin as a marker of the dense fibrillar component (DFC) $)^{11,48}$ were found in sparse spots inside of the nucleoli, which are almost completely excluded from the locations of $L E T N$ in the GC (Fig. $2 g, h$ ). This was supported by the low PCC values between LETN and either of the two proteins (Supplementary information, Fig. S13c), which were significantly lower than those between LETN and NPM1.

In summary, both the in vitro and in vivo assays above have demonstrated the direct binding between NPM1 and LETN, which nicely congregate in the GC of cell nucleoli. This inspired us to further study whether the potential molecular functions of the IncRNA LETN are related to the protein NPM1 (and vice versa).

Repression of the IncRNA LETN or the protein NPM1 results in identical phenotypes

As a nucleolar phosphoprotein, NPM1 is well known for playing crucial roles in a multitude of important intracellular processes, such as rDNA transcription, ribosome maturation, and nucleosome assembly. $^{49}$ As a result, NPM1 is essential for embryonic development and tumorigenesis. ${ }^{29}$ Indeed, knockdown of NPM1 significantly reduced the proliferation rates of $\mathrm{HUH7}$ and HCC827 cells (Supplementary information, Fig. S14), which was similar to the inhibitory effect of LETN repression on cell proliferation (Fig. 1).

Known as an essential and the most abundant protein in the nucleolus, ${ }^{19,20,24}$ NPM1 is critical for the structured formation of the nucleolus. ${ }^{20-23}$ As shown by electron microscopy images, knockdown of NPM1 resulted in largely disturbed nucleolar structures (Fig. 3a, more examples in Supplementary information, Fig. S15), which is consistent to the literature. ${ }^{23,50}$ Strikingly, similarly distorted nucleolus morphology was also observed upon knockdown of the IncRNA LETN (Fig. 3a, more examples in Supplementary information, Fig. S15).

In addition to the consistent phenotypic responses at the cellular level, we then tested whether repression of LETN or NPM1 may have affected the same molecular processes. From the global perspective, knockdown of LETN and NPM1 resulted in similar shifts of the gene expression profiles (Fig. 3b; Supplementary information, Fig. S16a), which were translated to the similar biological functions being perturbed by knockdown of LETN or NPM1 (Supplementary information, Fig. S16b). Specifically, knockdown of the IncRNA or the protein led to repression of the genes with highly focused functions such as chromatin and nucleosome assembly, DNA packaging, and protein-DNA complex assembly (Supplementary information, Fig. S16b).

NPM1 has been well recognized as a histone chaperone protein in the nucleolus, ${ }^{23,51-53}$ and a major function of NPM1 is facilitating nucleosome assembly and chromatin condensation. ${ }^{27}$ Knockdown of NPM1 dramatically increased the sensitivity of the chromatin to micrococcal nuclease (MNase) digestion, which indicates a substantial decrease in chromatin compaction (Fig. 3c). Consistently, knockdown of the IncRNA LETN resulted in a similar reduction in chromatin condensation (Fig. $3 \mathrm{C}$ ).

Another major function of NPM1 is driving rDNA transcription and ribosome maturation. ${ }^{19,20,24}$ siRNA- or ASO-mediated knockdown or CRISPR-mediated knockout of LETN resulted in decreased expression of $47 \mathrm{~S}$ pre-rRNA and mature rRNA (Fig. 3d; Supplementary information, Fig. S17a, b). This is consistent with the effect of NPM1 knockdown or knockout (Fig. 3d; Supplementary information, Fig. S17a). Northern Blots confirmed that the prerRNA was downregulated by knockdown of LETN or NPM1 (Supplementary information, Fig. S17c). Next, we showed that the repression of LETN or NPM1 reduced the newly synthesized nascent pre- and mature rRNAs, which were marked by the uridine analog 5-ethynyluridine (EU) (Fig. 3e). Overexpression of the InCRNA LETN led to elevated levels of the total pre- and mature rRNAs (Supplementary information, Fig. S17d) and the newly synthesized nascent pre- and mature rRNAs (Supplementary information, Fig. S17e). Finally, a dual-luciferase reporter system for the rDNA promoter showed that knockdown of LETN or NPM1 resulted in similarly reduced rDNA promoter activities (Supplementary information, Fig. S17f). It is worth nothing that when the general transcription was inhibited by Actinomycin $D$, the degradation rates of the rRNAs were unaffected by knockdown of either LETN or NPM1 (Supplementary information, Fig. S18). Taken together, the results above have illustrated the strong promotive effect of LETN in the process of rRNA synthesis, which is comparative to that of NPM1.

Inspired by the results above, and given the direct binding between LETN and NPM1, we proposed a hypothesis that the wellrecognized physiological functions of NPM1 may depend on the InCRNA LETN.

Oligomerization and nucleolar organization of NPM1 depend on LETN

NPM1 has a conserved $\mathrm{N}$-terminal oligomerization domain that mediates pentamerization of the protein. Multiple studies have shown that oligomerization of NPM1 is critical for its biological functions ${ }^{44,52,54-58}$ and that the disruption of the oligomeric status resulted in loss of its functions, such as histone binding and nucleosome assembly, ${ }^{33,34}$ rDNA transcription and ribosome maturation. ${ }^{35-37,59}$ Therefore, we tested the oligomerization of NPM1 with native polyacrylamide gel electrophoresis (PAGE), in which proteins retain their folded conformations and thereby oligomers can be separated from monomers. In control cells, endogenous NPM1 presents predominantly as polymers (likely pentamers according to the protein markers, Fig. 4a). Strikingly, upon knockdown of LETN, the NPM1 oligomers (>135 KDa) were greatly disrupted, and the monomeric NPM1 $(\sim 30 \mathrm{KDa})$ became the dominant form (Fig. 4a), indicating that the in vivo oligomerization of NPM1 requires the IncRNA LETN. Note that the total protein abundance of NPM1 was unaffected by LETN, as shown by the regular western blots from a denaturing procedure (Fig. 4a)

Co-immunoprecipitation of exogenously expressed GFP- and mCherry-tagged NPM1 also confirmed the interaction between 

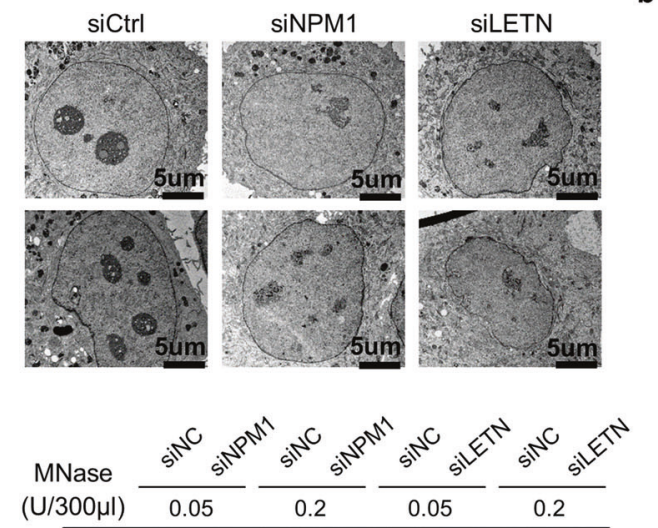

b
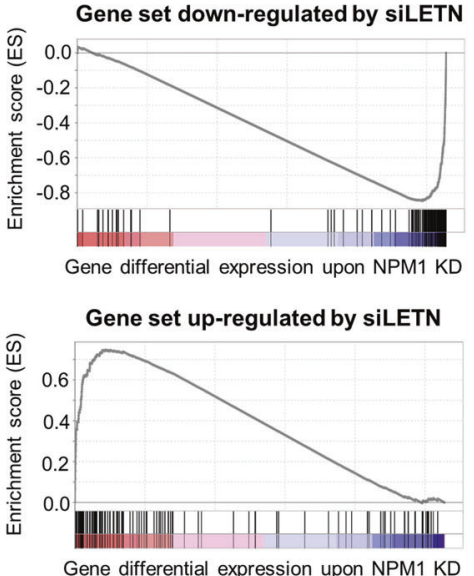

e

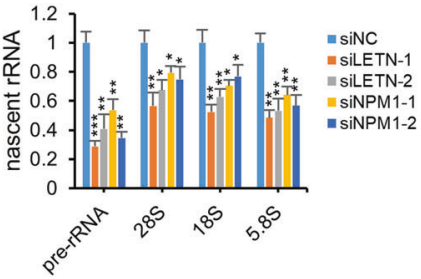

d

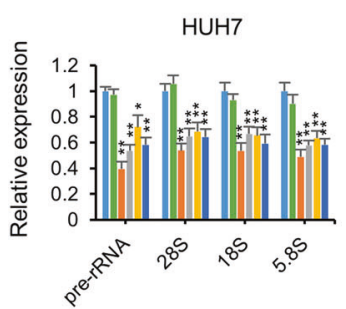

HCC827

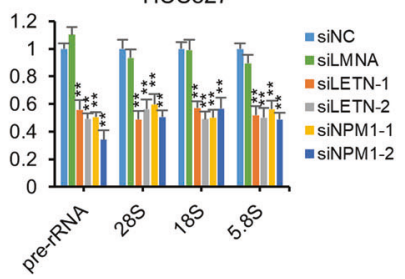

Fig. 3 Repression of the IncRNA LETN or the protein NPM1 leads to the same phenotypes. a Images of the nucleoli (obtained with TEM at $80 \mathrm{kV}$, 7000x) of HUH7 cells under the control and LETN or NPM1 knockdown conditions. b Gene set enrichment analysis plots showing enrichments of the gene sets that was downregulated or upregulated upon LETN knockdown in HUH7 cells, on the background of gene differential expression profile upon NPM1 knockdown. c MNase digestion assay. The chromatin of HUH7 cells was partially digested with MNase at different concentrations. The resulted DNA fragments were separated and visualized by gel electrophoresis. $\mathbf{d}$ Relative expression levels of pre- and mature rRNAs, normalized to beta-actin, measured by RT-qPCR in HUH7 and HCC827 cells upon LETN or NPM1 knockdown. Random siRNA or siLMNA were used as negative controls. Data show means \pm SD of three biological replicates. e Relative expression levels of the newly synthesized nascent pre- and mature rRNAs, which were marked by EU and measured by RT-qPCR, in HUH7 cells upon LETN or NPM1 knockdown. Newly synthesized beta-actin was used as a house-keeping gene for normalization. Data show means \pm SD of three biological replicates.

different NPM1 molecules, which was largely disrupted by knockdown of LETN (Fig. 4b). To further directly assess the closeness between NPM1 proteins, we used fluorescence lifetime imaging microscopy in combination with Förster resonance energy transfer (FLIM-FRET) assay. FLIM-FRET quantifies the shortening of fluorescence donor lifetime as a measurement of FRET efficiency, which indicates the proximity of the donor and acceptor. As shown in Fig. 4c, exogenous expression of mCherrytagged NPM1 significantly reduced the GFP lifetime in the cells expressing GFP-tagged NPM1, which confirms the closeness between NPM1 proteins under normal conditions. However, knockdown of LETN completely restored the GFP lifetime back to the level of the control, in which the mCherry-NPM1 as the energy acceptor is absent (Fig. 4c). This result again indicates that the close interaction between NPM1 proteins requires their binding partner, the IncRNA LETN.

In addition to the in vivo experiments above, in vitro assays also showed that the LETN RNA fragment of just the first $2000 \mathrm{nt}$, synthesized by in vitro transcription, greatly promoted pentamerization of the purified monomeric NPM1 protein in vitro, whereas the scrambled RNA with similar length failed to do so (Fig. 4d).
Importantly, LETN sequence lacking the three NPM1-binding fragments $(4,7$, and 13 as indicated in Fig. 2d) also failed to facilitate the NPM1 pentamerization (Fig. 4d).

NPM1 is predominantly localized in the GC of the nucleolus. $^{11,22,45,60,61}$ Furthermore, it is the NPM1 pentamer that serves as the main building block of the GC. ${ }^{20-22}$ Indeed, highresolution IF of the endogenous NPM1 with SIM illustrated roughly globular distribution patterns of NPM1 in the nucleoli of the control cells (Fig. 4e, f; 3D structures of the nucleoli reconstructed with SIM images of NPM1 are shown in Supplementary information, Video S6). However, upon knockdown of LETN, such highly organized distributions of NPM1, which mark the nucleolus GC morphology, were remarkably disrupted (Fig. 4e, f; 3D structures of the nucleoli are shown in Supplementary information, Video S8). Such disorder of the GC morphology by LETN knockdown was confirmed by the distribution of nucleolin (NCL), which is another marker of the GC (Supplementary information, Fig. S19; 3D structures of the nucleoli shown in Supplementary information, Videos S7 and S9). These data are also nicely consistent with our previous observation in Fig. 3a that knockdown of LETN or NPM1 resulted in distorted nucleolar morphology. In addition, we noted 

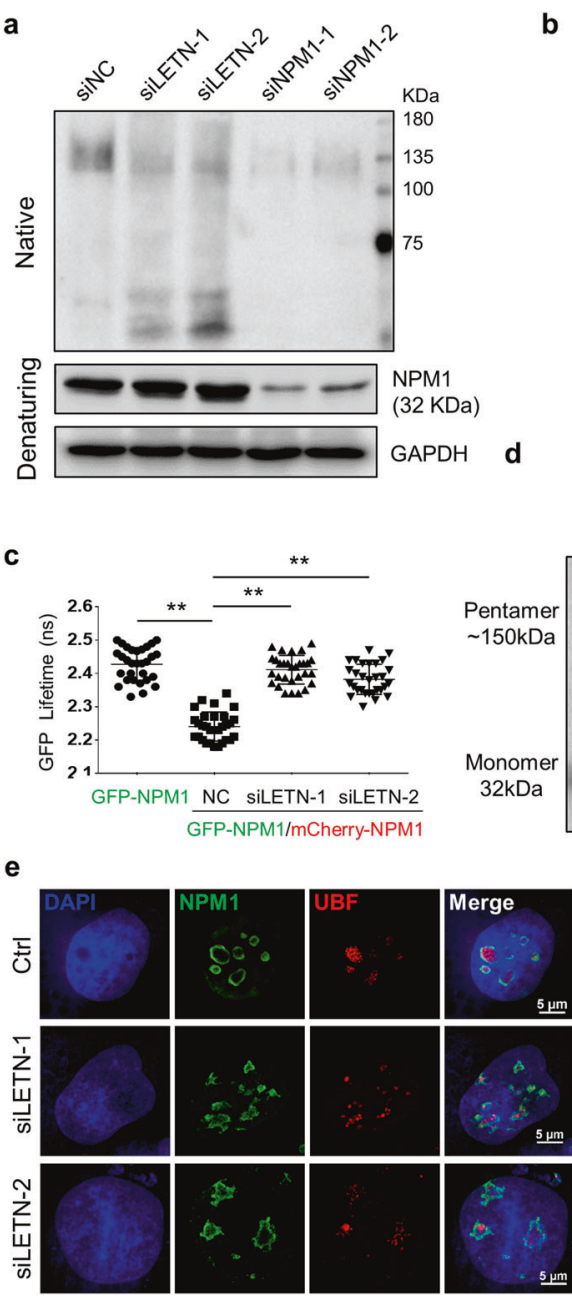

b

d
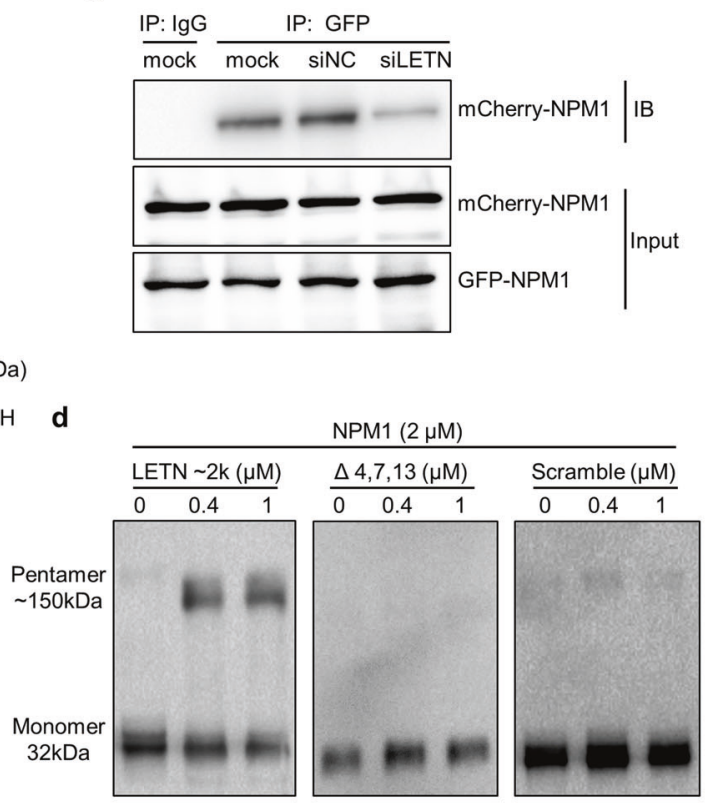

f

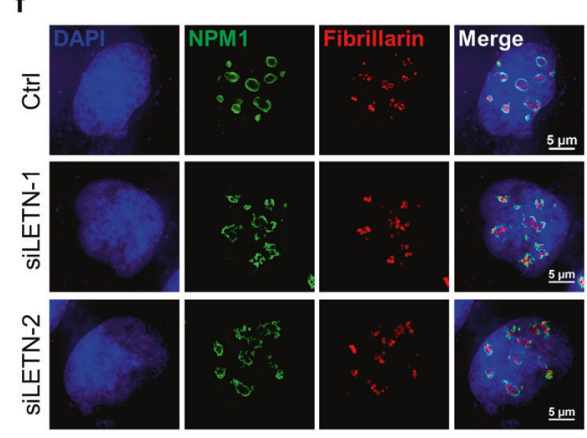

Fig. 4 The oligomerization and structural organization of NPM1 is dependent on LETN. a Upper, image of native PAGE with anti-NPM1 showing oligomeric and monomeric NPM1 proteins in HUH7 cells under conditions of LETN or NPM1 knockdown. Bottom, regular denaturing western blots showing the total protein level of NPM1. b GFP- and mCherry-tagged NPM1 were introduced into HUH7 cells by transfection. Co-immunoprecipitation of the exogenously expressed GFP- and mCherry-tagged NPM1 was performed to show the interactions between NPM1 proteins in control and LETN knockdown cells. c GFP- and mCherry-tagged NPM1 were introduced into HUH7 cells by transfection. The lifetime of GFP was quantified for 30 randomly selected cells, which indicates efficiency of energy transfer from GFP to mCherry. Cells with only the GFP-NPM1 served as a reference, in which there is no energy transfer as the acceptor fluorophore (mCherry) is absent. $\mathbf{d}$ In vitro assays with purified NPM1 monomeric protein, which was incubated for about 40 min with the first $2000 \mathrm{nt}$ of $L E T N$, the same LETN sequence but with the 3' NPM1-binding fragments removed, or scrambled RNA with a similar length. Images of native PAGE with anti-NPM1 show the oligomeric and monomeric NPM1 proteins. SIM images showing the nucleus staining by DAPI (blue) and IF of NPM1 (green), UBF (red, e), and fibrillarin (red, f) in $\mathrm{HUH7}$ cells.

that knockdown of LETN did not seem to disturb the FC and DFC of the nucleolus, which were marked by UBF and Fibrillarin, respectively (Fig. 4e, f; Supplementary information, Fig. S19 and Videos S6-S9).

Taken together, the results above showed that oligomerization of NPM1 in cells requires the IncRNA LETN. Under the condition of LETN repression, the NPM1 proteins can still be concentrated in the nucleoli, which is expected given the NoLS in the C-terminal region of NPM $1 .{ }^{44}$ However, as the polymerized NPM1, instead of the monomer, is critical for the formation of nucleolus, the nucleolus, specifically the GC, could not maintain its organized structure upon repression of LETN.

Mutual dependency between LETN and NPM1 in their molecular functions

As the major molecular functions of NPM1 were carried out by the oligomerized protein, which is indeed the dominating conformation of NPM1 (Fig. 4), it is a plausible hypothesis that the multiple molecular functions of NPM1 depend on the IncRNA LETN. Proteomic profiling of the NPM1-binding proteins showed that knockdown of the IncRNA LETN reduced the binding affinity of NPM1 to almost all of its binding partners (Fig. 5a), which are mostly histone proteins, ribosomal proteins, and some other proteins involved in RNA processing. (Supplementary information, Fig. S20). As a validation, our co-immunoprecipitation results clearly showed that the interactions between NPM1 and the histone proteins $\mathrm{H} 2 \mathrm{~A}, \mathrm{H} 2 \mathrm{~B}, \mathrm{H} 3$, and $\mathrm{H} 4$ were all largely weakened upon knockdown of LETN (Fig. 5b).

In fact, as introduced earlier in Fig. 3, one of the major functions of NPM1, facilitating nucleosome assembly and chromatin condensation, depends on its activity as a histone chaperone protein. It has been reported that both the $\mathrm{N}$ - and $\mathrm{C}$-terminal domains of NPM1 are essential for its oligomerization and functional activation. ${ }^{62}$ Therefore, as expected, after gene knockout of NPM1 with CRISPR, the re-expression of the $\mathrm{N}$ - or Cterminally truncated NPM1 (NPM1- $\Delta N / C$, Supplementary 
a

Abundance $(\log 2)$ of 259 proteins pulled-down by NPM1 IP
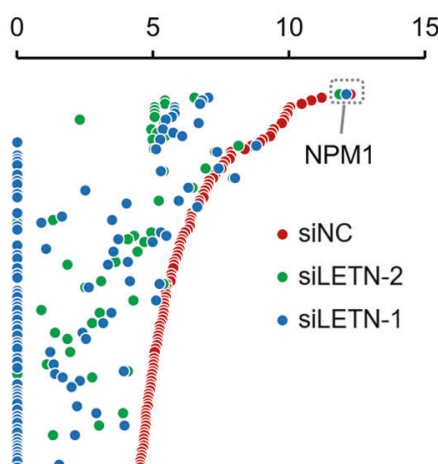

: $0 \dot{0}$

$\because$

-

-

$\cdots$

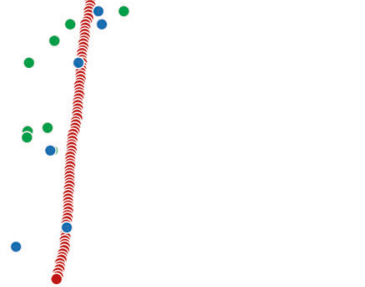

e

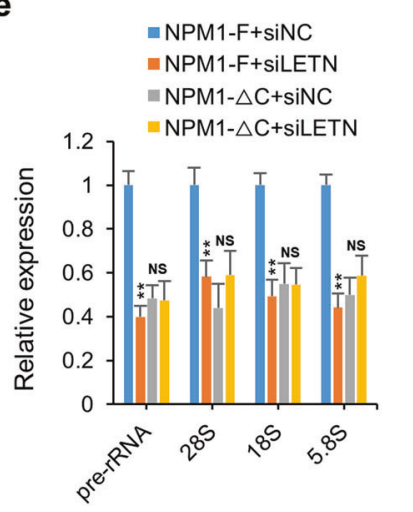

f b

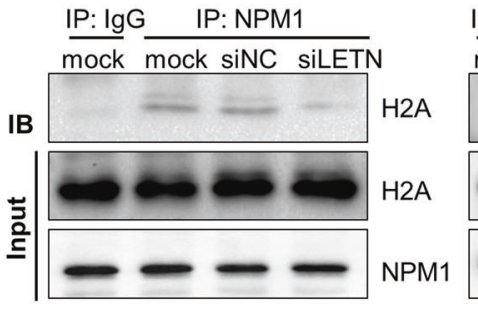

IP: IgG IP: NPM1

mock mock siNC siLETN
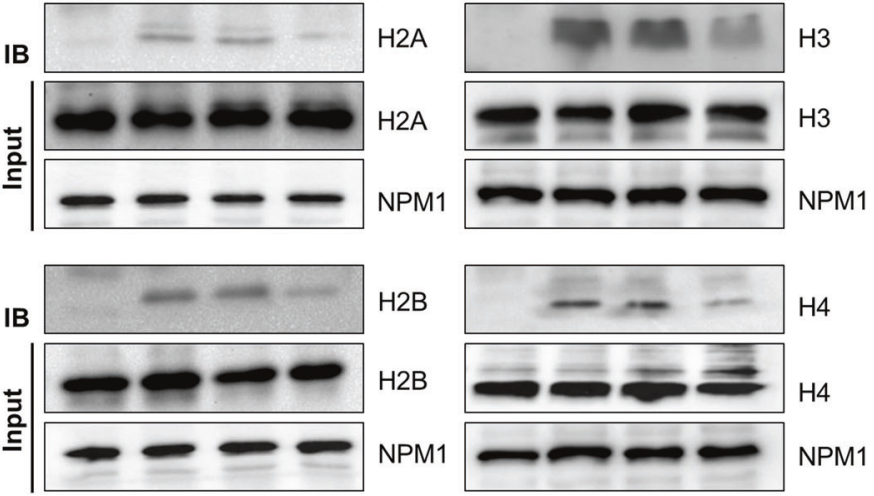

H2B

H2B

NPM1

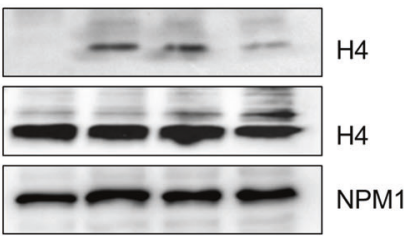

d

MNase $(0.05 \mathrm{U} / 300 \mu \mathrm{l})$ :

NPM1-F NPM1- $\triangle \mathrm{C}$

$\overline{\text { SiNC SILETN SINC SILETN }}$
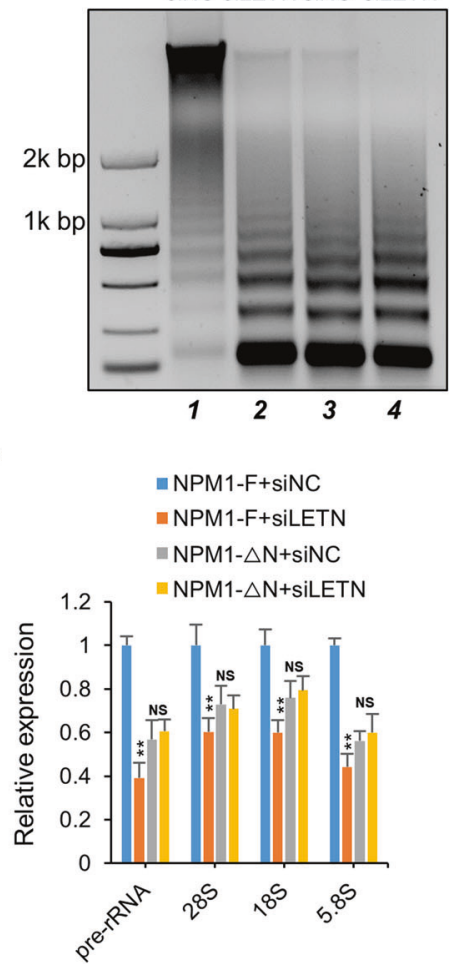

MNase $(0.05 \mathrm{U} / 300 \mu \mathrm{l})$ :

NPM1-F NPM1- $\triangle N$

SINC SILETN SINC SiLETN

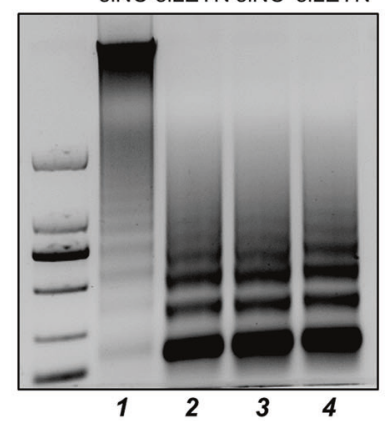

g

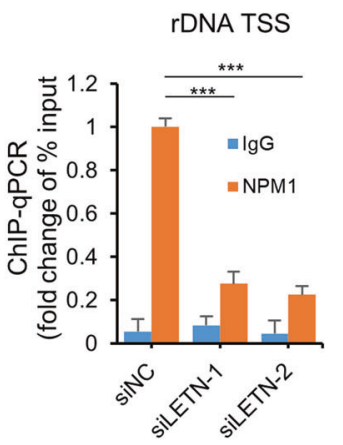

Fig. 5 Repression of LETN diminished the major molecular functions of NPM1. a Immunoprecipitation of NPM1 followed by mass spectrometry analysis of the proteins pulled down, in control and LETN knockdown HUH7 cells. As expected, the most abundant protein, NPM1, was consistent in control and LETN knockdown cells, thereby serving as a positive control. b Immunoprecipitation of NPM1 followed by immunoblotting of several histone proteins in $\mathrm{HUH} 7$ cells, with or without LETN knockdown. NPM1 ${ }^{-1-} \mathrm{HUH}$ cells were established by CRISPRmediated gene knockout. Full-length NPM1 (NPM1-F), C-terminus (NPM1- $\Delta$ C, 1-189 aa remaining, panel c, e) or N-terminus (NPM1- $\Delta$ N, 122-294 aa remaining, panel $\mathbf{d}, \mathbf{f})$ truncated NPM1 was then reintroduced into the NPM1 ${ }^{-/-}$cells. The chromatin of these cells upon siRNAmediated knockdown of LETN was partially digested with MNase $(0.05 \mathrm{U} / 300 \mu \mathrm{L})$. The resulted DNA fragments were separated and visualized by gel electrophoresis $(\mathbf{c}, \mathbf{d})$. Relative expression levels of pre- and mature rRNAs were measured by RT-qPCR upon LETN knockdown and normalized to the housekeeping gene beta-actin (e, f). The statistical significance levels were obtained by pair-wise comparisons between siNC and $\operatorname{siLETN}(\mathbf{e}, \mathbf{f})$. Data show means \pm SD of three biological replicates. $\mathbf{g}$ ChIP-qPCR assay of the rDNA promoter sequence after immunoprecipitation with anti-NPM1 in HUH7 cells. Data show means \pm SD of three biological replicates.

information, Fig. S21), instead of the full-length protein, failed to restore the compactness of the chromatin (Fig. 5c, d, comparing lane 3 vs lane 1). Importantly, upon knockdown of LETN, the fulllength NPM1 also lost its rescuing effect on chromatin condensation (Fig. 5c, d, comparing lane 1 vs lane 2).

Similarly, another major function of NPM1, promoting rRNA synthesis, was also dependent on LETN. Knockdown of LETN significantly restrained the rescue of rRNA expression upon reintroducing NPM1 into the NPM1 knockout cells (Fig. 5e, $\mathrm{f}$, comparing blue vs orange bars). ChIP analyses have demonstrated the direct binding of NPM1 to the genomic DNA around the rRNA gene promoter. ${ }^{19,63,64}$ Here, we further showed that LETN depletion significantly reduced the binding capacity of NPM1 to the rDNA promoter (Fig. $5 \mathrm{~g}$ ). In summary, LETN plays an 
672

indispensable role for the major functions of NPM1 in facilitating rRNA expression and chromatin condensation.

On the other hand, the molecular functions of LETN are executed mainly via NPM1. The data in Fig. 3 and Supplementary information, Figs. S14-S19 have shown that LETN knockdown led to disruptions of the cellular processes that are almost identical to those caused by NPM1 knockdown, whereas the overexpression of LETN did the opposite. Here, we further showed that the strong phenotypic consequences of LETN depletion (Fig. 5c-f) or overexpression (Fig. 6a-d) in HUH7 cells all depend on a fully functional NPM1 protein. Specifically, under the contexts of N- or C-terminally truncated NPM1, the cells were no longer responsive to knockdown or overexpression of the IncRNA LETN in terms of chromatin compactness (Fig. 5c, d for LETN knockdown and Fig. $6 \mathrm{a}, \mathrm{b}$ for overexpression, all by comparing lane 3 vs lane 4) and rRNA expression levels (Fig. 5e, f for knockdown and Fig. 6c, d for overexpression, all by comparing the gray vs yellow bars).

Last, in the NPM1 knockout HUH7 cells, the re-expressed exogeneous NPM1 (mCherry-labeled) showed nice coaggregation with the exogenously expressed LETN in the nucleolus (Fig. 6e, h), which is well-expected given our previous results in Figs. 2 and 4. However, NPM1- $\Delta$ C was found all around the nucleus, but not concentrated in the nucleolus (Fig. $6 \mathrm{f}$ ). This is because NPM1- $\Delta C$ lost its NoLS but retained its nuclear localization signal (NLS). Importantly, re-expression of NPM1- $\Delta$ C instead of the full-length protein blocked the nucleolar localization of the IncRNA LETN as well (Fig. 6f), and NPM1- $\triangle$ C showed almost no colocalization with LETN (Fig. 6f, h). As LETN binds to the C-terminus of NPM1 (Supplementary information, Fig. S11), the result above suggests that the nucleolar localization of LETN requires its binding with NPM1. In other words, the direct interaction between NPM1 and LETN is the cause, not a consequence, of LETN's nucleolar localization.

NPM1- $\triangle \mathrm{N}$ appeared to be enriched in the nucleolus (Fig. $6 \mathrm{~g}$ ), which is expected, as its C-terminal NoLS was intact. However, unlike the full-length NPM1, such partial aggregation of NPM1- $\triangle N$ was not accompanied by nucleolar colocalization with LETN (Fig. $6 \mathrm{~g}, \mathrm{~h}$ ). The $\mathrm{N}$-terminal region mediated the oligomerization of NPM1, which is critical for its biological function of facilitating the structural organization and molecular functions of the nucleolus. ${ }^{44,52,54-58}$ Therefore, these data further confirmed that the nucleolar localization of LETN depends on a fully functional and oligomerized NPM1 in the nucleolus. Finally, it is worth noting that under the condition of LETN knockdown, the general distribution patterns of the two truncated proteins NPM1- $\Delta C$ and NPM1- $\triangle N$ were consistent to those in the control cells (Supplementary information, Fig. S22 compared to Fig. 6f, g).

In summary, for NPM1, its oligomerization and structured aggregation in the nucleolar GC requires the IncRNA LETN; and for $L E T N$, its concentration in the nucleolus depends on the fully functional NPM1 protein. Such mutual dependency between NPM1 and LETN is crucial for their molecular functions in the nucleolus.

\section{Physiological relevance of the LETN-NPM1 interaction}

The results above have established a clear mutual dependency between the IncRNA LETN and the protein NPM1 in key molecular processes such as chromatin condensation and rRNA expression, which are crucial for fast proliferation of cells. As shown in Figs. 1 and $7 \mathrm{a}-\mathrm{d}$, overexpression or knockdown of LETN significantly accelerated or repressed cell proliferation, respectively. Such a strong phenotypic impact of LETN was only observed with the fulllength NPM1 protein (Fig. 7a-d, comparing the gray vs orange curves) but not with the $\mathrm{C}$ - or N-terminally truncated NPM1 proteins (Fig. 7a-d, comparing the yellow vs blue curves). On the other hand, the rescue of cell proliferation by full-length NPM1 was only achieved with normal (Fig. 7a-d, comparing the gray vs yellow curves, $P$-values $<0.01$ ) or overexpressed LETN (Fig. 7a, b, comparing the orange vs blue curves, $P$-values $<0.001)$, but not in the LETN knockdown cells (Fig. 7c, d, comparing the orange vs blue curves). Therefore, the LETN-NPM1 axis is critical for promoting and maintaining cancer cell proliferation.

Since cancer cells need hyperactive nucleoli to sustain fast cell proliferation, the nucleolar proteins would likely be associated with cancer patient prognosis. Indeed, the patients of liver cancer with lower expression levels of LETN or NPM1 had better prognosis (Fig. 7e). Furthermore, the patients with higher expression levels of both LETN and NPM1 showed the most aggressive cancer development that led to the worse prognosis (red curve in Fig. 7f), and by contrast, patients with lower expression levels of the both factors showed much better prognosis (green curve in Fig. 7f). Such association between the NPM1/LETN expressions and the patient survival supports the physiological relevance of the NPM1-LETN axis via its involvement in promoting the nucleolar functions.

In addition to the indispensable role in tumorigenesis, ${ }^{29-31}$ NPM1 has also been shown to be essential for embryonic development, especially in the forebrain. ${ }^{29}$ Given the dependency of NPM1 function on the InCRNA LETN, we further asked whether LETN is also critical for brain development. The expression of LETN is low in most adult human organs, and its relatively high expression was seen mainly during early gestational age (GA), especially in the fetal brain and cerebellum around GA weeks $7-10^{32}$ (Supplementary information, Fig. S1a). This is the stage of embryogenesis and early fetal development when the NPCs undergo fast proliferation. ${ }^{65}$ Indeed, we confirmed that the induction of human embryonic stem cell (ESC) H9 to NPCs coincides with increased expression of LETN (Supplementary information, Fig. S23), which was consistent with the data from another published study. ${ }^{66}$ Interestingly, upon LETN knockdown, the H9-induced NPCs showed largely repressed proliferation signal of Ki67 (Fig. 7g). Therefore, the IncRNA LETN is not only indispensable for tumor cell proliferation but also very likely to be relevant in normal organ development, for example, in fetal brain development.

\section{LETN-NPM1 interaction is associated with evolutionarily new} variations of NPM1

As a critical structural and functional nucleolar protein, NPM1 is highly conserved across organisms. However, the sequence of $L E T N$, like many other human IncRNA species, is not well conserved (Supplementary information, Fig. S24a). Similar genomic sequences of $L E T N$ can be found in multiple primates such as chimpanzee, gorilla, orangutan, etc., but not in most of the other vertebrates including the model animals mouse and rat (Supplementary information, Fig. S24a). Therefore, it is worth investigating why the highly conserved NPM1 in human cells depends on the IncRNA LETN that is absent in other species such as mouse.

After NPM1 knockdown in HUH7 cells, expression rescue with mouse or human NPM1 largely restored the cell proliferation rate (Supplementary information, Fig. S24b) and the rRNA expressions (Supplementary information, Fig. S24c). Interestingly, while the rescue effects of human NPM1 depend on the expression of LETN (Figs. 5-7; Supplementary information, Fig. S24b, c), mouse NPM1 restored the proliferation rates and the rRNA expressions equally with and without LETN (Supplementary information, Fig. S24b, c). These results suggest that although the NPM1 protein sequences are largely conserved across human and mouse, there is still a critical difference between these two versions of NPM1 in terms of their dependency on LETN.

Indeed, to our surprise, mouse NPM1, which was expressed in the NPM1 $1^{-1-}$ HUH7 cells, weakly binds to LETN, if not none at all (Fig. 8a), while similarly restored human NPM1 showed strong binding with LETN (Fig. 8a, also supported by other results above). Interestingly, under the similar context of NPM1 restoration in the $\mathrm{NPM}^{-/-} \mathrm{HUH7}$ cells, pentamerization of mouse NPM1 was not 
a

MNase (0.1U/300 $\mathrm{H})$ :

NPM1-F NPM1- $\triangle C$ EV LETN EV LETN

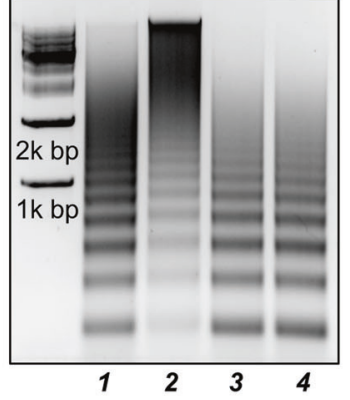

b MNase $(0.1 \mathrm{U} / 300 \mu \mathrm{l})$ : NPM1-F NPM1- $\triangle N$ EV LETN EV LETN

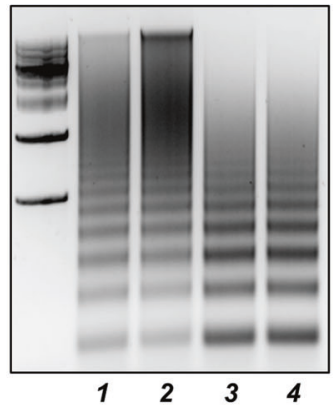

- NPM1-F+EV

- NPM1-F+LETN-OE

- NPM1- $\triangle \mathrm{C}+\mathrm{EV}$

- NPM1- $\triangle \mathrm{C}+\mathrm{LETN}-\mathrm{OE}$

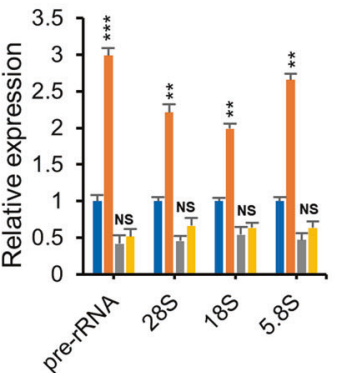

d

- NPM1-F+EV

NPM1-F+LETN-OE

- NPM1- $\triangle \mathrm{N}+\mathrm{EV}$

NPM1- $\triangle N+L E T N-O E$

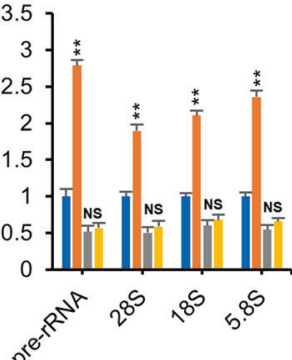

e
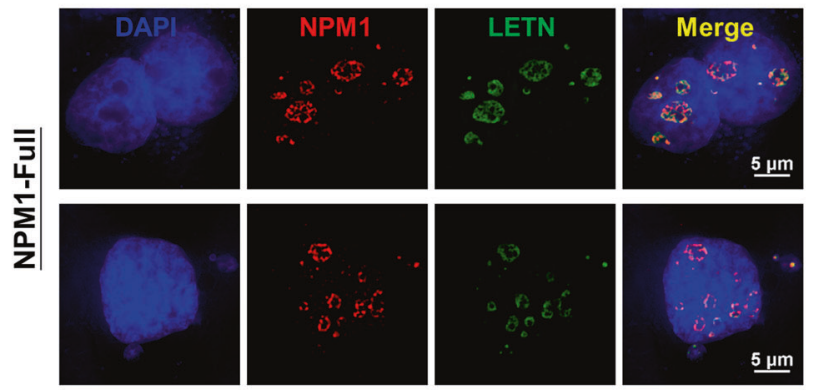

f
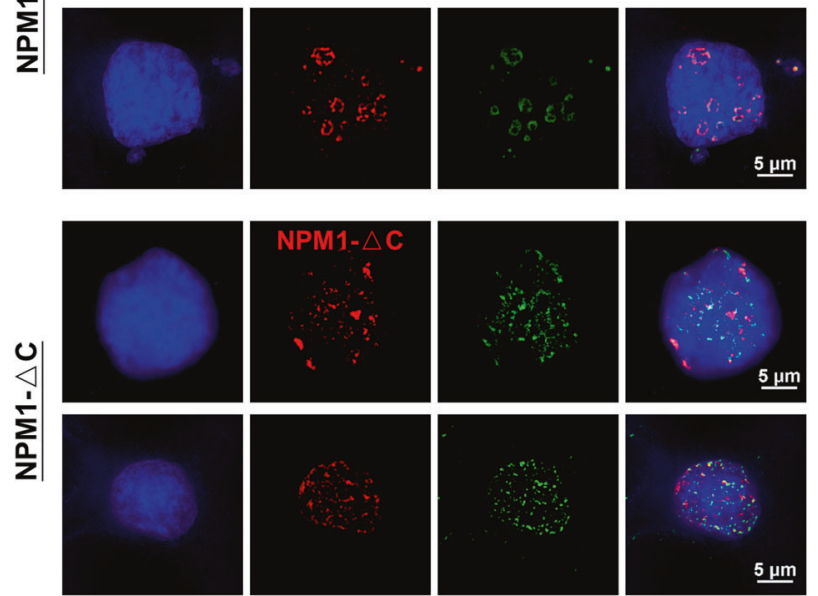

g
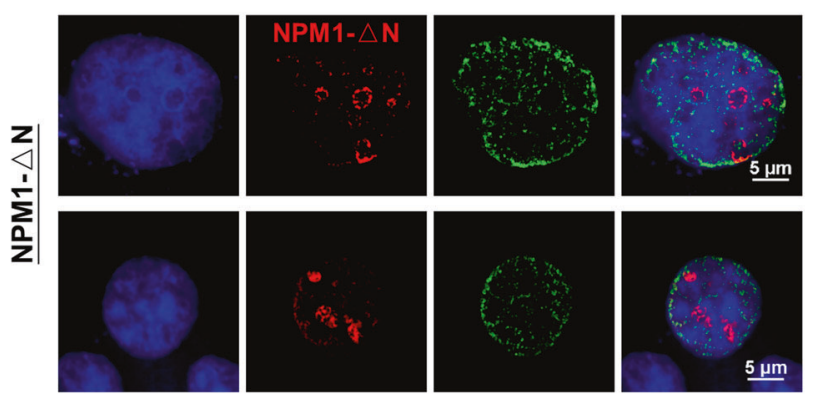

h

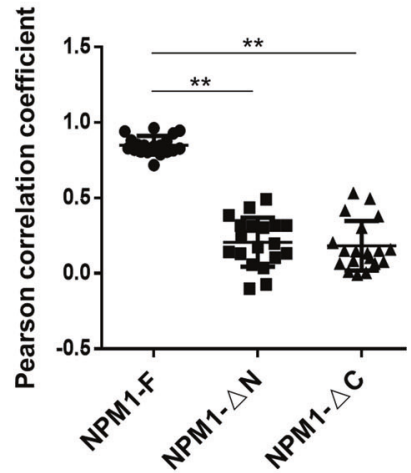

Fig. $6 \mathrm{~N}$ - or C-terminal truncation of NPM1 blocked the major molecular functions of LETN. a-d Full-length NPM1 (NPM1-F), C-terminustruncated NPM1 (NPM1- $\Delta$ C, panel $\mathbf{a}, \mathbf{c}$ ) or N-terminus-truncated NPM1 (NPM1- $\Delta \mathrm{N}$, panel $\mathbf{b}$, d) was reintroduced into the NPM1 ${ }^{-/-} \mathrm{HUH}^{-}$cells. The chromatin of these cells was partially digested with MNase $(0.1 \mathrm{U} / 300 \mu \mathrm{L})$ upon overexpression of $L E T N$. The resulted DNA fragments were visualized by gel electrophoresis $(\mathbf{a}, \mathbf{b})$. Relative expression levels of pre- and mature rRNAs were measured by RT-qPCR upon overexpression of LETN and normalized to the housekeeping gene beta-actin $(\mathbf{c}, \mathbf{d})$. The statistical significance levels were obtained by pair-wise comparisons between EV and LETN-OE $(\mathbf{a}, \mathbf{b})$. Data show means \pm SD of three biological replicates. e-g SIM images showing the nucleus staining by DAPI (blue), mCherry-labeled full-length NPM1 (e), NPM1- $\Delta$ C (f), or NPM1- $\Delta \mathrm{N}$ (g) (red), and MS2-tagged LETN marked by MS2-GFP (green) in the NPM1 ${ }^{-1-}$ HUH7 cells. $\mathbf{h}$ The degrees of colocalization between LETN and the NPM1 proteins were quantified by the Pearson's correlation coefficients (PCC). The maximal value of PCC (1.0) indicates perfect colocalization between two fluorescence signals in a cell, whereas PCC $=0$ indicates no colocalization.

affected by LETN knockdown at all, whereas human NPM1 largely shifted towards the monomeric states upon LETN knockdown (Fig. 8b). In addition to the in vivo experiments above, in vitro assays also showed that the purified mouse NPM1 proteins form pentamers easily without LETN and that the addition of LETN did not further promote the pentamerization (Fig. 8c). Compared to the results in Fig. 4d, this again exhibits an obvious difference between the human and mouse NPM1 proteins.

The N-terminal region of NPM1 (amino acids 1-121) is exactly the same between human and mouse, whereas the middle region 
b

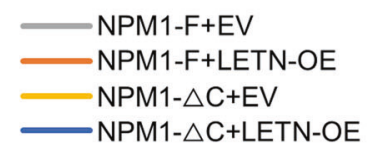

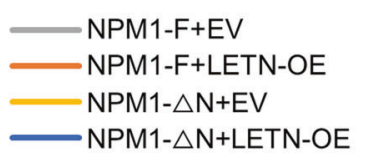

C

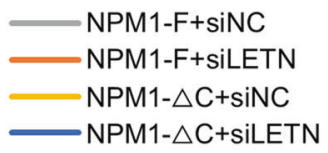

d

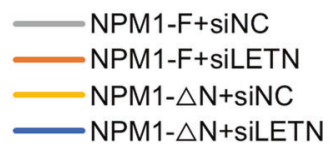

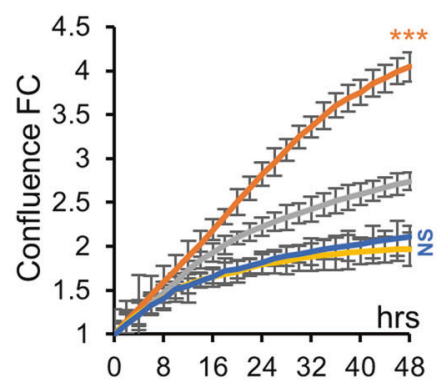
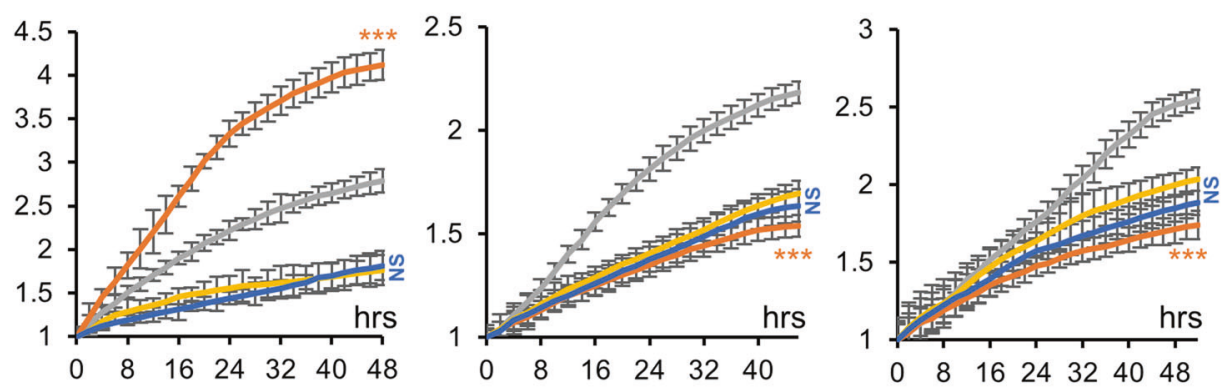

e
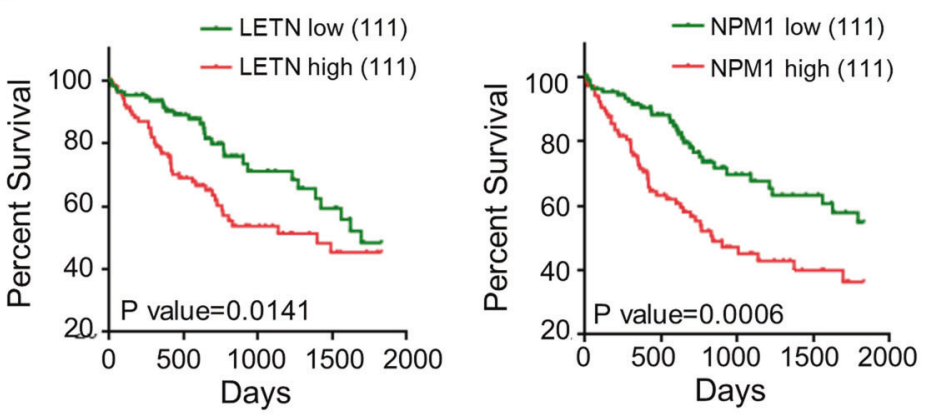

f

g
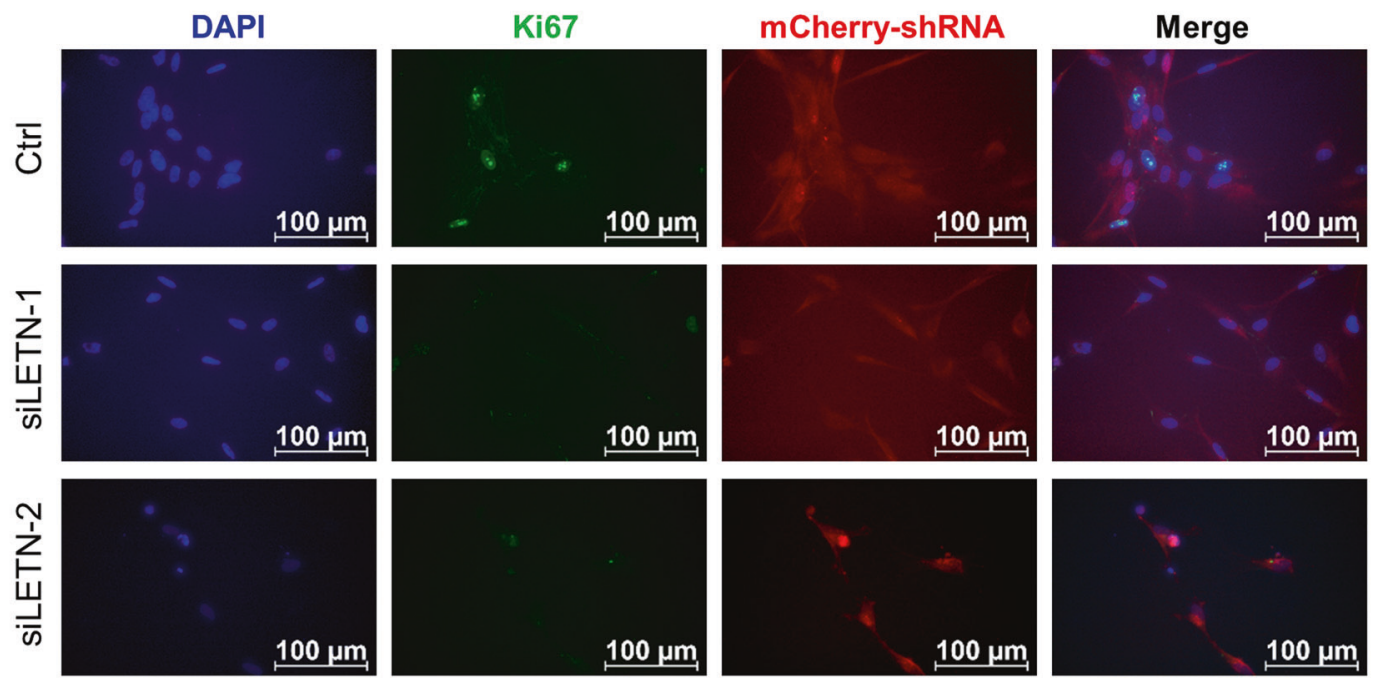

Fig. 7 Physiological relevance of $L E T N$ in liver cancer and NPC proliferation. a-d Proliferation curves of NPM1 ${ }^{-/-}$HUH7 cells expressing fulllength NPM1 (NPM1-F), NPM1- $\triangle$ C, or NPM1- $\Delta \mathrm{N}$, upon overexpression (a, b) or siRNA-mediated knockdown (c, d) of LETN. The statistical significance levels were obtained by pair-wise comparisons between EV and LETN-OE (a, b), or between siNC and siLETN (c, d). The error bars represent the \pm SD of three biological replicates. e, $\mathbf{f}$ Liver cancer patients in TCGA were partitioned into subgroups according to the expression levels of LETN or NPM1 in the tumors. Kaplan-Meier survival curves were prepared for the subgroups of patients with LETN or NPM1 expression above the top 30th percentile or below the bottom 30th percentile (e). Next, intersections among the four groups above partitioned these patients further into four new subgroups (LETN low/high \& NPM1 low/high). Kaplan-Meier survival curves for these subgroups were prepared (f). P-values were obtained with log-rank tests. g Proliferation signals shown by Ki67 staining in NPC cells derived from H9 ESC cells. The shRNA vectors used in this experiment were labeled with mCherry.

(122-189) harbors a few mutations (Supplementary information, Fig. S25a). This region, also known as an intrinsically disordered region, is highly enriched by acidic residues and therefore responsible for the binding of NPM1 to histones. ${ }^{51,53}$ Normally, this function is unlikely to be affected by the few variations within this region. Importantly, we have already shown that binding with LETN takes place in the C-terminal part of NPM1 (residues 190-294, Supplementary information, Fig. S11). Compared to the mouse NPM1, this C-terminal region of human NPM1 harbors mutations at four residues, i.e., 190 (Val to Ala), 196 (Val to lle), 214 

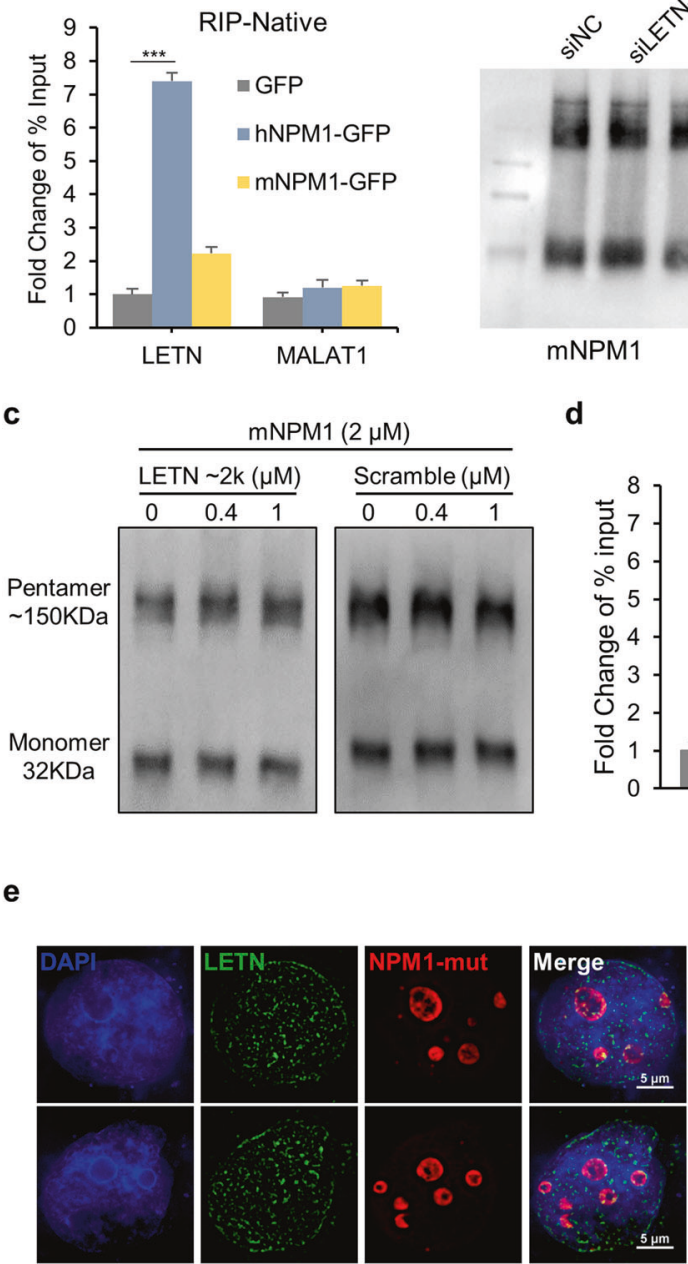

d b
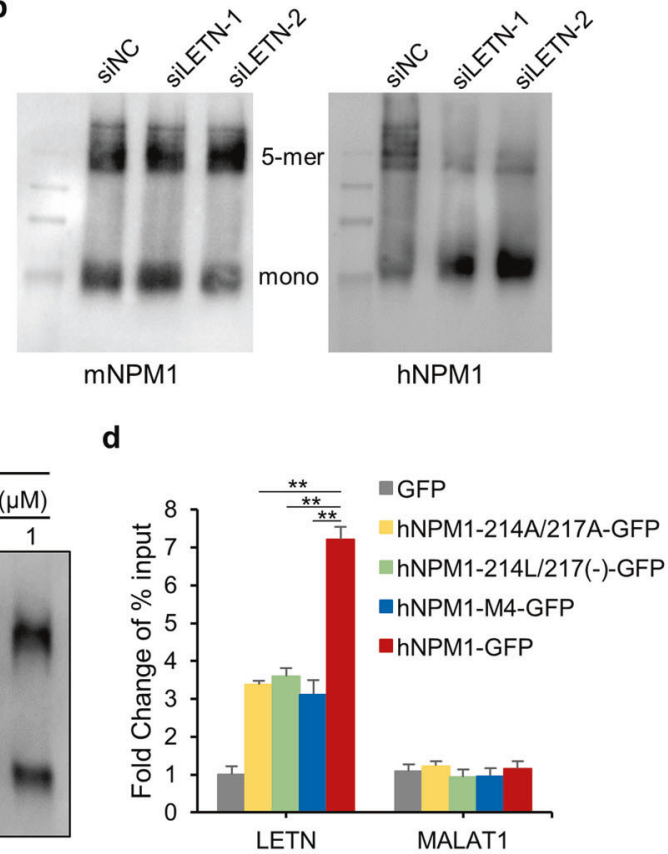

f

hNPM1-214A/217A (2 $\mu \mathrm{M})$

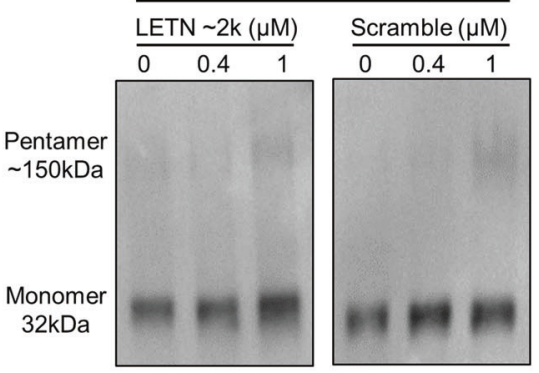

Fig. 8 Differences between human and mouse NPM1 in the interactions with LETN. a GFP-tagged human or mouse NPM1 was reintroduced into the NPM1 ${ }^{-1-}$ HUH7 cells. qPCR of LETN and MALAT1 was performed after native cross-linking GFP-RIP. MALAT1 was used as a negative control. The error bars represent the \pm SD of three biological replicates. b Human or mouse NPM1 was reintroduced into NPM1 ${ }^{-1-} \mathrm{HUH7}$ cells. Native PAGE was used to show the oligomeric and monomeric NPM1 proteins under the conditions of LETN knockdown. c In vitro assays with purified mouse NPM1 monomeric protein, which was incubated for about 40 min with LETN fragment of the first 2000 nt or scrambled RNA with a similar length. Images of native PAGE with anti-NPM1 show the oligomeric and monomeric NPM1 proteins. d GFP-tagged human wildtype or mutant NPM1 at the two residues (214 and 217) or at the three residues altogether (M4) was reintroduced into NPM1 ${ }^{-1-} \mathrm{HUH}$ cells. qPCR of LETN and MALAT1 was performed after native cross-linking GFP-RIP with the cells. MALAT1 was used as a negative control. The error bars represent the \pm SD of three biological replicates. e SIM images showing the nucleus staining by DAPI (blue), mCherry-labeled NPM1214A/217A mutant protein and LETN (green) in the NPM1 ${ }^{-1}$ HUH7 cells. $f$ In vitro polymerization with purified human NPM1-214A/217A mutant protein, which was incubated for about $40 \mathrm{~min}$ with LETN fragment of the first $2000 \mathrm{nt}$ or scrambled RNA with a similar length. Images of native PAGE with anti-NPM1 show the oligomeric and monomeric NPM1 proteins.

(Leu to Ser), and 217 (Ser insertion) (Supplementary information, Fig. S25a). Due to the similar physicochemical properties between Val and Ala/lle, the first two mutations are unlikely to result in significant functional changes of the protein. Therefore, we suspected that the newly acquired functional dependency of human NPM1 on LETN could be attributed to these four residues, most likely to the latter two Ser residues.

In the NPM1 rescue experiment with $\mathrm{NPM}^{-1-} \mathrm{HUH7}$ cells, converting any of these four residues of human NPM1 to the mouse version only slightly reduced its binding affinity with LETN, whereas combinatory mutation of all four of them largely abolished its binding with LETN (Supplementary information, Fig. S25b). Note that the same level of binding blockage with LETN was achieved by mutating just the two Ser residues 214 and 217, to their mouse homologs or to the non-phosphorylatable mimic Ala (Fig. 8d). In vitro assays also confirmed that the human NPM1-214A/217A mutant proteins almost completely lost their binding capacity with
LETN (Supplementary information, Fig. S25c). Consistently, as its NoLS signals are intact, the human NPM1-214A/217A mutant proteins were enriched in the nucleolus (Fig. 8e), whereas LETN was found spread in the nucleus, rather than being enriched in the nucleolus like it was in the cells with wild-type human NPM1 (Fig. 8e, comparing to Figs. 2 and 6). Furthermore, in vitro NPM1 polymerization assays showed that the human NPM1 mutant (hNPM1-214A/217A) does not form pentamers with or without LETN (Fig. 8f). Therefore, the two Ser sites are critical for the interaction between LETN and NPM1, which controls the pentamerization and the molecular functions of NPM1.

From the other way around, conversion of the mouse NPM1 to the human homologs at the two residues or the four residues altogether largely restored its binding with LETN to the same level (Supplementary information, Fig. S25d). In vitro NPM1 polymerization assays showed that the mutation of mouse NPM1 (mNPM1214S/217S) blocked the protein pentamerization (Supplementary 
information, Fig. S25e). However, LETN strongly reactivated the pentamerization of the mouse NPM1 mutant (mNPM1-214S/217S) (Supplementary information, Fig. S25e). Together, the results above suggest that these two Ser residues are predominately responsible for the NPM1-LETN interaction in human. Indeed, the combination of these two Ser residues is only found in primates, which is well in line with the conservation patterns of the LETN-like sequences (Supplementary information, Fig. S26). Therefore, it appears that the LETN-NPM1 interaction is associated with the evolutionarily new variations of NPM1 and the coordinated emergence of the IncRNA. Such a protein-IncRNA interaction renders an additional yet critical layer of regulation for the nucleolar functions that sustain fast cell proliferation.

\section{DISCUSSION}

Great efforts have been dedicated to functional annotations of the non-coding transcriptomes in human and other species. $^{5-7,9,10,32,67}$ In general, the scale of the non-coding genome is associated with the complexity of the species. ${ }^{2}$ Hundreds of IncRNAs are associated with a large variety of normal biological activities and disease processes. ${ }^{6,7}$ Studies have indicated that many of these IncRNAs function as fine-tuners rather than key players in processes such as development or disease..$^{5,9,10,67}$ In the present study, we found that a previously uncharacterized IncRNA, which we renamed as LETN, plays an indispensable role in facilitating the molecular functions of NPM1 that shape the organized nucleolus structure and sustain cell proliferation. There are several open reading frame (ORF) candidates in the LETN sequence. However, based on bioinformatic assessments of their coding potentials with CPAT ${ }^{68}$ and validations with several mass spectrometry datasets and ribosome profiling data ${ }^{69}$ from tissues of liver, liver tumor, and cancer cell lines, we did not see any support of peptide coded by any of these ORFs. Finally, as shown in our manuscript, LETN is primarily located in the nucleolus. Therefore, LETN should mainly function as a non-coding RNA and it is unlikely to produce any peptide or protein.

NPM1 is a well-studied nucleolar chaperone protein that is essential for the assembly of the nucleolus. ${ }^{19,20,24}$ It is highly abundant and has been shown to play critical roles in key processes, such as ribosome biogenesis and chromatin condensation. ${ }^{19,20,24-28}$ Strikingly, these major functions of NPM1 all depend on the IncRNA LETN. On the other hand, the physiological relevance of LETN was mainly mediated by the highly powerful protein NPM1. Eventually, we showed that this mutual interaction between LETN and NPM1 is essential for the proliferation of cancer cells and potentially NPCs. Therefore, LETN is a rare case of the IncRNAs with fundamental biological activities and high physiological relevance.

The nucleolus is a crucial organelle for fundamental processes such as rDNA transcription and ribosome biogenesis. ${ }^{11}$ Previously, several IncRNAs have been reported to facilitate major functions of the nucleolus. For example, the IncRNA PAPAS, an antisense transcript to pre-rRNA functioning in cis, can help recruit CHD4/ NuRD to the rDNA promoter and repress rDNA transcription at elevated temperature. ${ }^{14}$ Upregulated PAPAS in quiescent cells results in increased H4K20me3 at rDNAs and repressed transcription. ${ }^{15}$ The IncRNA SLERT is another example of nucleolar IncRNAs, which acts in trans and derepresses Pol I transcription of rDNA by binding to DDX21 and loosening the DDX21 ring. $^{16}$ Another InCRNA, HOXB-AS3, was reported to guide the ErbB3-binding protein 1 (EBP1) to the rDNA, therefore promoting the rRNA transcription. ${ }^{17}$ While being influential on the nucleolar functions, none of these nucleolar IncRNAs has been reported to be impactful on the structure of the nucleolus itself. From this perspective, LETN is unique, as it is essential for the normal organized structure and multiple major functions of the nucleolus, which is supported by the strong phenotypic responses of cancer cells and NPCs to the repression of LETN.
The nucleolus has been well recognized as a typical membraneless organelle composed of different compartments and formed by liquid-liquid phase separation (LLPS). ${ }^{22,70-72}$ The oligomerized NPM1 protein, as pentamers, exhibits multivalency in binding with arginine-rich linear motifs (R-motifs) and rRNA, which enables heterotypic LLPS. ${ }^{20}$ The pentameric ring of NPM1 also undergoes homotypic assembly via LLPS. $^{21}$ These multiple LLPS processes have been proposed to be simultaneously operational and essential for the dynamic liquid-like features of the nucleolus. ${ }^{20,21}$ Furthermore, the different surface tensions of the liquid droplets composed of different proteins define the core-shell structure of the nucleoli, of which the GC is enriched with NPM1. ${ }^{22}$ This implies that the organization of the nucleolus is a dynamic process and that the nucleoli could have multiple states with potentially differential functional activities. First, the sizes of the nucleoli have been shown to be well related to the rates of cancer cell proliferation. ${ }^{73}$ In addition, while the well-recognized roundshaped nucleoli have been frequently shown in literature, other reticulated nucleoli have also been reported, ${ }^{74,75}$ mostly in the normal non-proliferative cells. Such distorted nucleoli appear quite similar to the nucleoli morphology upon LETN knockdown (Figs. 3a, 4e, f) or NPM1 knockdown ${ }^{23,50}$ (Fig. 3a). Therefore, based on the results of our study, we propose that NPM1-LETN plays a critical role in ensuring the hyperactive nucleolar state, to which cancer is known to be 'addicted' for rapid growth. ${ }^{76}$

Focusing on the nucleolar GC morphology, we noted that the SIM images showing the IF staining of the endogenous NPM1 and NCL (Fig. 4e, f; Supplementary information, Fig. S19) do not appear perfectly consistent with the time-lapse live cell images in Fig. 2e, Supplementary information, Fig. S13b and Videos S1-S5. The SIM images have leveraged the high resolution to illustrate the fluorescence distributions on a thin cross-section of the nucleolus. Therefore, the peripheral mass (i.e., GC) of the nucleolus presents a nearly ring-shaped distribution pattern on a single SIM image. The 3D structures of the nucleoli reconstructed with multiple SIM images at different depths on the $z$-axis show the nucleolar GC much clearer (Supplementary information, Videos S6-S9). In addition, although our IF staining experiments have been extensively optimized, the possibility of reduced accessibility of the intra-nucleolar proteins by the antibodies cannot be completely ruled out. However, this possibility does not dampen the observation that knockdown of LETN perturbed the nucleolar morphology. On the other hand, the time-lapse microscopy of live cells just shows the overall colocalization between LETN and the mCherry-labeled NPM1. Although the time-lapse images occasionally captured the ring-shaped NPM1 and LETN distribution patterns as well, their resolution and sensitivity were not high enough to illustrate the detailed distribution of NPM1 or LETN on a single cross-section of the nucleolus.

Importantly, it is the NPM1 pentamer, instead of the monomer, that forms the fundamental building blocks of the LLPS processes. The studies above illustrated that the purified NPM1 forms pentamers and undergoes LLPS, and we also saw predominance of the pentamers formed by purified NPM1 in vitro. These data suggest that the NPM1 pentamers, once formed, are stable in vitro without LETN. However, we have showed that oligomerization of NPM1 in vivo depends on the IncRNA LETN. Furthermore, after breaking most of the oligomers into monomers by sonication (Fig. 4d), LETN, but not scrambled RNA, greatly facilitated reoligomerization of the monomeric NPM1 in vitro (Fig. 4d). Therefore, based on the results above altogether, we propose the following potential scenario. The IncRNA LETN, being recruited by NPM1 into the nucleoli, facilitates the formation of the NPM1 pentamer, which then takes a central position in shaping the nucleolus and sustaining the nucleolar functions. Due to the high abundance of NPM1 in the nucleolus, the IncRNA is restrained in the nucleolus and reused for many rounds of NPM1 pentamerization. In other words, the LETN-NPM1 interaction is a one-to-many 
type, and this explains why the relatively small number of the LETN molecule play such a critical role in facilitating the pentamerization of NPM1, which is much more abundant than LETN.

Finally, the current study has been focused on the nucleolar functions depending on NPM1 and LETN, as both factors are highly enriched in the nucleoli. However, some results also indicated potentially extra-nucleolar functions of NPM1 and LETN. For example, knockdown of LETN or NPM1 seems to have a rather global effect on the chromatin condensation (Fig. 3c), which is unlikely to be just limited in the nucleolus. In fact, although NPM1 has been best-characterized as a nucleolar protein, it also carries out various functions outside of the nucleoli (for example ${ }^{77}$ ). Interestingly, previous studies have identified other NPM1interacting IncRNAs that regulate the extra-nucleolar functions of NPM1. For example, SAMD12-AS1, activated by HBV-encoded $\mathrm{HBx}$, titrates away NPM1 from the E3 ligase HDM2, which resulted in increased p53 degradation. ${ }^{78}$ In the present study, we have also observed sparse distributions of NPM1 occasionally in the nucleoplasm, and very interestingly, LETN was found to colocalize with NPM1 even outside of the nucleoli (for example Fig. 6e). Therefore, we suspect that these extra functions of NPM1 outside of the nucleolus are very likely to be related to its colocalization with LETN as well. Such extra-nucleolus functions of the NPM1LETN axis is certainly worth clarifying in the future.

\section{MATERIALS AND METHODS}

Survey of functional IncRNAs in cancers

We adapted the conceptual design of the Modulator Inference using the Network Dynamics (MINDy) algorithm ${ }^{79}$ and developed a data-mining pipeline to search for the IncRNAs that exhibited modulatory functions on the gene regulatory circuits from transcription factors to their target genes. Previously, we have used the same methodology to similarly infer the DNA methylation sites that modulate the transcriptional regulatory circuits, ${ }^{80}$ and to identify the transcription factors whose activities on the target gene expressions depend on the level of a specific IncRNA, NEAT1. ${ }^{81}$

The large-scale mRNA and IncRNA expression data of tumor samples in The Cancer Genome Atlas (TCGA) was used for the analysis, which was done in a cancer type-specific manner for 20 major cancers in TCGA (manuscript under review). The present study was based on the results in liver cancer. Specifically, in liver cancer, the IncRNA ENST00000564237.1 (RP11-196G18.22) was predicted to modulate the largest number of transcriptional regulation circuits, i.e., pairs of transcription factors and their target genes, suggesting that this IncRNA potentially serves as a powerful determining factor of the gene expression programs in liver tumors.

Analysis of the DNA copy number and RNA expression data from TCGA

The pan-cancer copy number variation (CNV) data in TCGA were downloaded from UCSC Xena (http://xena.ucsc.edu/). GISTIC2 threshold method was applied using the TCGA FIREHOSE pipeline to produce gene-level copy number estimates. Subsequently, as done previously in literature, ${ }^{82,83}$ the CNV values were partitioned into five groups: $-2,-1,0,1,2$, representing homozygous deletion, single copy deletion, diploid normal copy, low-level copy number amplification, or high-level copy number amplification, respectively.

As previously described, ${ }^{84}$ RNA-seq V2 data (level 3) were used for LETN expression profiles in tumor and adjacent normal samples from 22 cancer types in TCGA. These are read counts of genes and have been already processed and normalized across all the samples of each cancer type by TCGA with the upper quantile normalization method.
Cell culture

Cell lines were purchased from American Type Culture Collection (ATCC) and cultured in a humidified incubator with $5 \% \mathrm{CO}_{2}$ at $37^{\circ}$ C. HUH7 and HCC827 cells were cultured in Dulbecco's modified Eagle medium (high glucose, Corning). PC3 cells were cultured in Roswell Park Memorial Institute 1640 (RPMI-1640, Corning), and DU145 cells were cultured in Eagle's Minimum Essential Medium (MEM, Corning). All the media were supplemented with $10 \%$ fetal bovine serum (HyClone).

Estimation of LETN RNA copy numbers per cell

Different concentrations of RNA spike-in was added into the total RNA extracted from 30,000 cells with TRIzol. The RNA samples were then subjected to reverse transcription followed by qPCR analysis. The serial dilution of RNA spike-in was used to generate the standard curve, which shows the Ct values for the RNA copy numbers in 30,000 cells. The copy number of LETN per cell was then estimated by fitting its $\mathrm{Ct}$ value on to the standard curve.

\section{$5^{\prime}$ - and $3^{\prime}$-RACE}

The InCRNA LETN full length containing the transcriptional initiation and termination sites was confirmed by $5^{\prime}$ - and $3^{\prime}$-RACE using the SMARTer RACE $5^{\prime} / 3^{\prime}$ Kit (Takara Bio USA, Cat. Nos. 634858 ) by following the manufacturer's protocol. The genespecific primers (GSPs) were designed for 5'-RACE (5'TCACCAT TACCGCTACATAGTACG $\left.3^{\prime}\right)$ and $3^{\prime}$-RACE (5'GAGACATGCCACC ATATTTAGG3') PCR.

Vector construction, small interfering RNA (siRNA) synthesis and transfection

Full-length LETN was PCR-amplified by Q5 High-Fidelity DNA Polymerase (NEB) from genomic DNA of $\mathrm{HUH7}$ cells. The PCR product was cloned into the EcoRI and Notl sites of the pcDNA3.1 vector. To generate the pcDNA3.1-MS2 and pcDNA3.1-LETN-MS2 vectors, the MS2-12× fragment was PCR-amplified by Q5 HighFidelity DNA Polymerase (NEB) from pSL-MS2-12× (Addgene) and cloned into the Notl and Xbal sites of pcDNA3.1 and pcDNA3.1$L E T N$, respectively.

The cDNA of the NPM1 fragments (NPM1.1, NPM1.2, NPM1.3 as shown in Supplementary information, Fig. S11), truncated NPM1 (NPM1- $\Delta \mathrm{N}$ (amino acids 122-294 remaining) and NPM1- $\Delta C$ (amino acids 1-189 remaining)), or NPM1 full-length were PCRamplified by Q5 High-Fidelity DNA Polymerase (NEB) and cloned into the EcoRI and Notl sites of pLV-mCherry or pLV-GFP vectors.

The siRNAs specifically targeting LETN, NPM1, B2M and LMNA, and non-targeting control siRNA were synthesized by GenePharma. siB2M and siLMNA served as negative controls. ASO specifically targeting LETN and control ASO-NC were synthesized by RiboBio. Cells were transfected with the plasmids, siRNAs, or ASO using Lipofectamine 2000 or Lipofectamine RNAiMAX Reagent (Invitrogen), respectively, following the manufacturer's protocol.

\begin{tabular}{lll}
\hline Oligos & Sense 5'-3' & Antisense 5'-3' \\
\hline siLETN-1 & GCUGUCUCCAUGUCUUCUU & AAGAAGACAUGGAGACAGC \\
siLETN-2 & GCUCUCUGCUCAAGUAUUA & UAAUACUUGAGCAGAGAGC \\
siNPM1-1 & CCGACAAAGAUUAUCACUU & AAGUGAUAAUCUUUGUCGG \\
siNPM1-2 & GGAAGAUGCAGAGUCAGAA & UUCUGACUCUGCAUCUUCC \\
siB2M & UACAAGAGAUAGAAGACCAG & CUGGUCUUUCUAUCUCUUGUA \\
siLMNA & AUCUCAUCCUGAAGUUGCUUC & GAAGCAACUUCAGGAUGAGAU \\
siNC & ACGUGACACGUUCGGAGAA & UUCUCCGACGUGUCACGU \\
ASO- & GGCUGUCUCCAUGUCUUCUU & AAGAAGACAUGGAGACAGCC \\
LETN & &
\end{tabular}


678

Lentivirus production and construction of stable cell lines

For overexpression, the full-length LETN was cloned into the EcoRI and SgrAl sites of pLV-mCherry-N vector, named as LETN-OE. For shRNA-mediated knockdown, two pairs of CDNA oligonucleotides targeting LETN were designed and synthesized. After annealing, double-strand oligonucleotides were inserted into pLVshRNAmCherry $(2 \mathrm{~A})$ puro vector, named as shLETN-1 and shLETN-2. A scrambled shRNA was used as negative control.

The individual lentiviral expression vector was mixed with the packaging plasmid $\Delta 8.9$ and VSVG. The plasmids were cotransfected into HEK293T cells with Lipofectamine 2000 (Invitrogen). After $48 \mathrm{~h}$, the medium was collected and passed through a $0.45 \mu \mathrm{m}$ filter. The cells were infected by the medium with $8 \mu \mathrm{g} /$ $\mathrm{mL}$ of polybrene. After $24 \mathrm{~h}$ of infection, the medium was removed, and the cells were selected with puromycin.

\begin{tabular}{lll}
\hline shRNA & Sense 5'-3' & Antisense 5'-3' \\
\hline shLETN-1 & GGACTTCCAGTTAAGCCAATT & AATTGGCTAAACTGGAAGTCC \\
shLETN-2 & GGCTGTCTCCATGTCTTCTTA & TAAGAAGACATGGAGACAGCC \\
shNC & ACGTGACACGTTCGGAGAAA & TाCTCCGAACGTGTCACGT
\end{tabular}

Knockout of LETN or NPM1 by CRISPR/Cas9

The sgRNAs targeting LETN or NPM1 were individually inserted into PX458 plasmid (Addgene), which also expresses GFP. The plasmids were transfected into HUH7 cells with Lipofectamine 2000 reagent (Invitrogen). The positive cells which expressed GFP protein were screened by FACS and the knockout efficiency was detected by RT-qPCR.

\begin{tabular}{ll}
\hline sgRNA & Sequence $5^{\prime}-3^{\prime}$ \\
\hline sgLETN-1 & TCAAATTCAGTCGGAACTC \\
sgLETN-2 & GAGACGATATGCTACGGGTG \\
sgNPM1-1 & GCGCAGGACGGCTACGGTAC \\
sgNPM1-2 & GTAACTATCATCAGGAGGT \\
Scramble sgRNA-1 & GAACGTTGGACTACTTCAC \\
Scramble sgRNA-2 & GCGCCTAAGAGTACTCATC
\end{tabular}

Cell proliferation and colony formation assays

After different types of gene perturbations, the cells were cultured in 48-well plates, at the starting density of 20,000 cells per well. The IncuCyte live-cell imaging and analysis system (ESSEN Bioscience) was used to monitor real-time cell proliferation and morphology changes. Cell proliferation was quantified by measuring the occupied area (\% confluence) in the cell images over time. The proliferation curves were made with confluence fold change (FC) at different time points in relative to the confluence at time 0 .

For colony formation assays, 1000 cells were seeded in the 6well plates and incubated with normal growth medium for 14 days. Then cells were fixed and stained with $0.5 \%$ crystal violet for $15 \mathrm{~min}$. Lastly, the colonies were imaged via a camera or a microscope. For the anchorage-independent colony formation assay, the cells were collected, resuspended in culturing media containing $10 \% \mathrm{FBS}$ and $0.3 \%$ agarose (Amresco), and then seeded on top of $0.6 \%$ agarose gel containing $10 \%$ FBS in six-well plates. The cells were cultured in regular media for 3-4 weeks, and the colonies were stained with crystal violet and photographed.

In vivo xenograft assay

Xenograft animal models were established with male athymic $\mathrm{BALB} / \mathrm{c}$ nude mice (6 weeks old). First, cells (3 million for the LETN knockdown experiment or 1 million for overexpression) were injected into the left or the right flanks of mice subcutaneously. Tumors were allowed to grow for 4-5 weeks. The tumor volume was measured every 7 days and calculated as $0.5 \times$ a (long diameter) $\times \mathrm{b}^{2}$ (short diameter). At the end, the mice were sacrificed, and the tumors were isolated, photographed and weighed. All the mouse studies have been approved by the Institutional Animal Care and Use Committee at Tsinghua University.

RNA extraction and real-time $\mathrm{qPCR}$ analysis

Total RNA was isolated using the TRIzol reagent (Invitrogen) following the manufacturer's instructions. The first-strand cDNA was generated using a High-Capacity cDNA Reverse Transcription Kit (Invitrogen, 4368814) and diluted 1:10 in nucleasefree water to use as a template for qPCR. Real-time qPCR was carried out with SYBR Green Master MIX (Invitrogen) and the gene-specific primers were shown as follows. The gene expression values in relative to the house-keeping genes GAPDH or beta-actin were calculated by the Ct differences $(\Delta \mathrm{Ct})$, and the fold change of the gene expression in relative to the control sample were calculated by the difference between the $\Delta \mathrm{Ct}$ values $(\Delta \Delta C)$.

\begin{tabular}{lll}
\hline Gene ID & Forward primer 5'-3' & Reverse primer 5'-3' \\
\hline LETN-1 & GGGTCTACCTGTGAACTGTGA & GGAAACACATGTGGCAGCAC \\
LETN-2 & TGGTTCTGGCAGCATAACT & AGCCTGGGCAACAAGAGTGA \\
NPM1-N & TTCGGTTGTAACTAAAGGC & CAAGGGAAACCGTGGCTGT \\
NPM1-C & TCTGTAGAAGACATTAAAG & AATAGCCTCTTGGTCAGTCAT \\
& CAAA & \\
Pre-rRNA & GCCTTCTCTAGCGATCTGAGAG & CCATAACGGAGGCAGAGACA \\
18S rRNA & TCCTTGGTCGCTCGCTCCT & GATCTGATAAATGCACGC \\
& & ATCCC \\
5.8S rRNA & ACTCGGCTCGTGCGTC & GCGACGCTCAGACAGG \\
28S rRNA & GCGGGTAAACGGCGGGAGTA & TTGGCTGGGTTCGCTGGAT \\
Spike in & TAAACAGGATACCCGTCAT & ATCGCCGTCGCTGATGGAGT
\end{tabular}

NEAT1 TTCACCTGCTCTGGCTCTTG GCCAGGCACCGTGTTATACT

HOTTIP CCTAAAGCCACGCTTCTITG TGCAGGCTGGAGATCCTACT

HOTAIR GGGGCTTCCTTGCTCTTCTTATC GGTAGAAAAAGCAACCACG

SLERT TTAGTCAGCTCAGGCCCAGT AAGTGCTCCACCAACTCCAG

NESTIN GCGGCTGCGGGCTACTGAAA CCAGGAGGGTCCTGTACG

TGGC

NONOG CAATGGTGTGACGCAGAAGG TGCACCAGGTCTGAGTGTTC

GAPDH GGTCACCAGGGCTGCTITTA TTCCCGTTCTCAGCCTTGAC

ACTB TGGACATCCGCAAAGACCTG CCGATCCACACGGAGTACTT

(beta-actin)

MALAT1 GCTCTGTGGTGTGGGATTGA GTGGCAAAATGGCGGACTIT

Northern blotting

For the northern blot assay, $5 \mu \mathrm{g}$ total RNA was resolved by agarose gel electrophoresis, followed by transferring to a nylon membrane. The membrane was then subjected to UV crosslinking $\left(120 \mathrm{~mJ} / \mathrm{cm}^{2}\right)$ immediately, followed by pre-hybridization for $1 \mathrm{~h}$ at $68^{\circ} \mathrm{C}$, and then hybridization with DIG labeled probes for $16 \mathrm{~h}$ at $68^{\circ} \mathrm{C}$. After blocking with the blocking buffer (Roche, 11585762001), the membrane was incubated with anti-DIG-AP antibody. The antisense probe was synthesized with the DIG RNA labeling Mix (Roche) and SP6 polymerase (Thermo). The antisense probe sequences are TCAGCTCTCTGCTCAAGTA and ACATGTT AAGCATACTGCGG for LETN, GAGAACGCCTGACACGCAGG and 
GCTGACACGCTGTCCTCT for Pre-rRNA, and CCGATCCACACGGAGTACTT and AGAAAATCTGGCACCACACC for beta-actin.

\section{Labeling of newly synthesized nascent RNAs}

To capture the newly synthesized nascent RNAs, $0.2 \mathrm{mM}$ EU was added to the culture medium for $24 \mathrm{~h}$. EU-incorporated RNAs were biotinylated and captured by using the Click-iT Nascent RNA Capture Kit (Invitrogen, MP10365) in accordance with the manufacturer's instructions.

Western blotting and native polyacrylamide gels Cells were harvested and lysed with RIPA lysis buffer (Solarbio) supplemented with $1 \mathrm{mM}$ PMSF and protease inhibitor cocktail (Roche, 4693124001). Lysate was quantified using the BCA protein assay (Pierce). The cell lysate containing $30 \mu \mathrm{g}$ proteins was prepared in a $1 \times$ SDS buffer and heat-denatured. Then sample was subjected to $10 \%$ SDS-PAGE, followed by transferring to a NC membrane. After blocking using 3\% BSA, the membrane was incubated with the primary and secondary antibodies. The protein bands were visualized and quantified with the SuperSignal West Pico Chemiluminescent HRP substrate (Thermo) and imaged on the Molecular Imager ChemiDox XRS System from Bio-Rad. AntiNPM1 (1:2000, ab10530), anti-GFP (1:2000, ab290), anti-Histone H2A (1:2000, EPR17470, ab177308) and anti-Histone H2B (1:2000, EP957Y, ab52599) were purchased from Abcam, anti-Histone H3 (1:2000, 17168-1-AP), anti-Histone H4 (1:1000, 16047-1-AP) and anti-GAPDH $(1: 5000,60006-1-\mathrm{lg})$ were purchased from Proteintech. Secondary anti-rabbit and anti-mouse were purchased from Pierce Biotechnology.

For Native gel electrophoresis, the cells were lysed with RIPA buffer without SDS, supplemented with $1 \mathrm{mM}$ PMSF and protease inhibitor cocktail (Roche, 4693124001), followed by short-lived sonication. The cell lysates were mixed with $4 \times$ Protein Native PAGE Loading Buffer (TaKaRa, 9175) without heating and then loaded into native PAGE gels without SDS. The other procedures were the same as regular protein gel electrophoresis.

Isolation of cytoplasmic and nuclear RNA

The cells were harvested and lysed with $200 \mu \mathrm{L}$ lysis buffer $(50 \mathrm{mM}$ Tris, pH 8.0, $140 \mathrm{mM} \mathrm{NaCl}, 1.5 \mathrm{mM} \mathrm{MgCl} 2,0.5 \% \mathrm{NP}-40,2 \mathrm{mM}$ Ribonucleoside Vanadyl Complex). After incubation on ice for 10 $\mathrm{min}$, the lysate was centrifuged at $1000 \mathrm{rpm}$ for $3 \mathrm{~min}$ at $4^{\circ} \mathrm{C}$. The supernatant was enriched by cytoplasmic fraction, and the nuclear fraction was in the pellet. The pellet (nuclear fraction) was collected and resuspended in lysis buffer (without NP-40).

For nucleolus isolation, the pellet (nuclear fraction) was dissolved with resuspension buffer I (340 mM sucrose and $5 \mathrm{mM}$ $\mathrm{MgCl}_{2}$ ), followed by sonication until the pellet was completely resolved. The equal volume of resuspension buffer II $(880 \mathrm{mM}$ sucrose and $5 \mathrm{mM} \mathrm{MgCl}$ ) was added, followed by centrifugation at $2000 \mathrm{rpm}$ for $20 \mathrm{~min}$ at $4{ }^{\circ} \mathrm{C}$. The supernatant was enriched by the nucleoplasmic fraction, and the nucleolus fraction was in the pellet. Finally, TRIzol was used to extract RNA from the cytoplasmic, nucleoplasmic and nucleolus fractions. ${ }^{16,85}$

Chromatin condensation assay by MNase digestion

200,000 cells were harvested and lysed with $2 \mathrm{~mL}$ lysis buffer I (50 $\mathrm{mM}$ HEPES with the $\mathrm{pH}$ at $7.6,140 \mathrm{mM} \mathrm{NaCl}, 1 \mathrm{mM}$ EDTA, $10 \%$ glycerol, $0.5 \% \mathrm{NP}-40$, and $0.25 \%$ Triton $\mathrm{X}-100$ ) for $30 \mathrm{~min}$ at $4{ }^{\circ} \mathrm{C}$. The lysate was centrifuged at $1000 \mathrm{rpm}$ for $5 \mathrm{~min}$, and the supernatant was discarded. The pellet (chromatin fraction) was washed with lysis buffer II (10 mM Tris-Cl at pH 8, $200 \mathrm{mM} \mathrm{NaCl}, 1$ mM EDTA, $0.5 \mathrm{mM}$ EGTA) and then $10 \mathrm{mM}$ Tris-Cl buffer at pH 7.5. The chromatin pellet was dissolved with MNase digestion buffer (10 mM Tris-Cl at pH 7.5, $50 \mathrm{mM} \mathrm{NaCl}, 5 \mathrm{mM} \mathrm{MgCl} 2,1 \mathrm{mM} \mathrm{CaCl}_{2}$, $0.075 \% \mathrm{NP}-40$ ) containing MNase (concentrations indicated on the figures) for $5 \mathrm{~min}$ at $37^{\circ} \mathrm{C}$ on a rotating platform. The MNase reaction was stopped by adding the Stop solution (5\% SDS and 50
mM EDTA). The DNA fragments were isolated by PCl (Phenol: Chloroform:Isoamyl Alcohol (25:24:1)) extraction and analyzed on $1 \%$ agarose gels.

RNA sequencing and differential expression analysis

Total RNA was extracted with TRlzol reagent, following the manufacturer's protocol. The Ribozero Kit (Epicentre) was used to remove ribosomal RNA. The ribosomal RNA-depleted RNA was used for sequencing library preparation with a NEB Next Ultra Directional RNA Library Prep Kit (NEB). Next-generation sequencing was performed on the Illumina HiSeq $X$ Ten system.

Truseq library $2 \times 150$ reads from total RNA sequencing were first pre-processed using Cutadapt to remove adapters and trim low-quality bases from $5^{\prime}$ and/or $3^{\prime}$ ends. After discarding reads shorter than $20 \mathrm{bp}$, paired-end reads were mapped to the hg19 genome using STAR (v1.2.15), with ENSEMBLE V75 reference annotation and the default parameters. Differential gene expression analyses were performed with the $\mathrm{R}$ package DEseq2. In the results, the genes with $\mid \log _{2}$ Fold change $>1$ and $P$-value less than $10^{-5}$ were deemed as significantly upregulated or downregulated and used for downstream analyses.

Functional annotations and gene set enrichment analysis For the various gene sets from different analyses, GO enrichment analysis was conducted using the Metascape tool. The GO terms with $P$-values $<0.001$ were selected and visualized by clusterProfiler. Each GO term was color-coded according to the $P$-value $\left(-\log _{10}\right)$ of the enrichment. The size of each node is proportional to the number of genes belonging to the GO term.

RNA fluorescence in situ hybridization (FISH) and immunofluorescence microscopy

The RNA-FISH assay was performed as previously described. ${ }^{81} \mathrm{~A}$ $0.856 \mathrm{~kb}$ fragment of LETN was amplified using the primer set (TCAGCTCTCTGCTCAAGTA and ACATGTTAAGCATACTGCGG). The fragment was then cloned into pGEM-T (Promega). The LETN probe was synthesized with DIG RNA labeling Mix (Roche) and SP6 polymerase (Thermo), according to the manufacturers' instructions.

The immunofluorescence assays were done as previously described. ${ }^{81,86}$ Coverslips in 24-well plates were pretreated with 50 $\mu \mathrm{g} / \mathrm{mL}$ poly-D-lysine (Beyotime) before planting the cells. The cells were fixed with $4 \%$ formaldehyde solution and $1 \%$ acetic acid mixture for $10 \mathrm{~min}$ and then washed with $1 \times$ PBS solution for three times at room temperature (RT). Subsequently, the cells were permeabilized with $0.5 \%$ Triton X-100 in PBS solution for $5 \mathrm{~min}$, rinsed, and then blocked with 3\% BSA in TBST at RT for $1 \mathrm{~h}$. The slides were then incubated with primary antibody diluted in blocking solution at $4{ }^{\circ} \mathrm{C}$ overnight. The slides were washed with TBST and then incubated with the secondary antibodies for Alexa Fluor 488 (1:400, Donkey anti-Mouse, abcam), Alexa Fluor 594 (1:400, Donkey anti-sheep, abcam) at RT for $1 \mathrm{~h}$. The coverslips were stained with 1 $\mathrm{mg} / \mathrm{mL}$ DAPI (Sigma) for $5 \mathrm{~min}$ and washed three times for $5 \mathrm{~min}$ with TBST. Next, cells were mounted on a slide with Prolong Gold Antifade Mountant (Thermo) and stored in a dark chamber. The slides were imaged with an inverted Nikon N-SIM/A1 microscope which is a combination SIM and laser scanning confocal microscope.

Colocalization of the fluorescence signals for each cell was quantified by the method of Pearson's correlation coefficients (PCC). ${ }^{46}$ The maximal value of PCC (1.0) indicates perfect colocalization between two fluorescence signals in a cell, whereas $\mathrm{PCC}=0$ indicates no colocalization. Specifically, the analysis was done with the NIS-Elements-AR software by following the software instruction. For each condition, about 20 cells were randomly selected, and their PCC values were reported.

Time-lapse microscopy

HUH7 cells were cultured on $20 \mathrm{~mm}$ glass bottom cell dish and co-transfected with pLV-NPM1-mcherry, pMS2-GFP and 
680

pcDNA3.1-LETN-MS2 plasmids. After $24 \mathrm{~h}$, cells were put under a Nikon A1R HD25 Confocal Microscope supplemented with live cell imaging environment control system. Cells were photographed every $15 \mathrm{~min}$ for up to $12.5 \mathrm{~h}$. All of the time-lapse images were processed using Imaris $\times 649.3 .1$ software.

FLIM-FRET assay

FLIM-FRET measures donor-receptor energy transfer and was performed as previously described. ${ }^{87}$ HUH7 cells were transfected with LETN siRNA or control siRNA in advance. Twenty-four hours later, cells were transfected with GFP-NPM1 and mCherry-NPM1 plasmids. After $48 \mathrm{~h}$, the cells were carried out on FV1200 Confocal/FLIM/FCS (Olympus). In brief, GFP fluorescence was excited at $488 \mathrm{~nm}$, emission decays were collected on the pixelby-pixel basis in the epi-fluorescence mode. The proximity should be manifested by shortening of GFP fluorescence lifetime since excitation is then transferred from the donor eGFP to the acceptor mCherry. The lifetime images were generated by a robust 'fast-FLIM' approach. FLIM data were analyzed by the SymPhoTime64 software (PicoQuant). FRET is demonstrated by shortening of the eGFP lifetime in cells. In all experiments, about 30 cells were measured in each group.

\section{MS2bp-GFP RNA pull down}

pcDNA3.1-MS2 or pcDNA3.1-LETN-MS2 was co-transfected with pMS2-GFP (Addgene) into HUH7 cells. After $48 \mathrm{~h}$, cells (10 million) were harvested and lysed with $1 \mathrm{~mL}$ native lysis buffer ( $50 \mathrm{mM}$ Tris, $\mathrm{pH}$ 7.4, $150 \mathrm{mM} \mathrm{NaCl}, 0.5 \%$ NP-40, $0.5 \mathrm{mM}$ PMSF, $2 \mathrm{mM}$ RVC, protease inhibitor cocktail (Roche)) followed by sonication. After centrifuging at $12,000 \mathrm{rpm}$ for $30 \mathrm{~min}$ at $4{ }^{\circ} \mathrm{C}$, the supernatant was pre-cleared with $10 \mu \mathrm{L}$ Dynabeads Protein-G. The samples were then incubated with GFP antibody ( $3 \mu \mathrm{g}$ per reaction; ab290, abcam) for $2 \mathrm{~h}$ at $4{ }^{\circ} \mathrm{C}$, followed by addition of $20 \mu \mathrm{L}$ Dynabeads Protein-G to the mixture and incubation overnight at $4{ }^{\circ} \mathrm{C}$ on a rotating shaker. Next, the samples were washed with wash buffer (50 mM Tris, pH 7.4, $300 \mathrm{mM} \mathrm{NaCl,} \mathrm{0.5 \%} \mathrm{NP-40,} 0.5 \mathrm{mM}$ PMSF, $2 \mathrm{mM}$ RVC, protease inhibitor cocktail (Roche, 4693124001)) for four times at $4{ }^{\circ} \mathrm{C}$. Finally, the magnetic beads were resuspended in $20 \mu \mathrm{L} 1 \times$ SDS loading buffer and boiled for $10 \mathrm{~min}$. The samples were analyzed by $10 \%$ SDS-PAGE and visualized by Fast Silver Stain Kit (P0017s, Beyotime) according to the manufacturer's instructions. The proteins were recovered from the bands and subjected to mass spectrometry analysis.

\section{RIP assays}

RIP was performed as previously described. ${ }^{16}$ For the native RIP assay, 10 million HUH7 cells were harvested and lysed with $600 \mu \mathrm{L}$ RIP buffer (50 mM Tris, pH 7.4, $150 \mathrm{mM} \mathrm{NaCl}, 0.5 \%$ NP-40, $0.5 \mathrm{mM}$ PMSF, 2 mM RVC, protease inhibitor cocktail (Roche, 4693124001)), followed by sonication (power 10 for four cycles, $10 \mathrm{~s}$ for sonication and $50 \mathrm{~s}$ for rest). After centrifuging at 12,000 rpm for $15 \mathrm{~min}$, the supernatant was pre-cleared with $10 \mu \mathrm{L}$ Dynabeads Protein $\mathrm{G}$. The samples were then incubated with $3 \mu \mathrm{g}$ of antiNPM1 antibody (ab10530, abcam) for $2 \mathrm{~h}$ at $4{ }^{\circ} \mathrm{C}$, and $20 \mu \mathrm{L}$ Dynabeads Protein-G were added to the mixture and incubated overnight at $4{ }^{\circ} \mathrm{C}$ on a rotating shaker. Next, the antibody-bead slurry was washed five times at $4{ }^{\circ} \mathrm{C}$ with wash buffer $(50 \mathrm{mM}$ Tris, $\mathrm{pH} 7.4,300 \mathrm{mM} \mathrm{NaCl}, 0.5 \% \mathrm{NP}-40,0.05 \%$ sodium deoxycholate, $0.5 \mathrm{mM}$ PMSF, $2 \mathrm{mM}$ RVC, protease inhibitor cocktail (Roche, 4693124001)). The RNA-protein complex was resuspended with proteinase $\mathrm{K}$ buffer $(117 \mu \mathrm{L}$ of wash buffer, $15 \mu \mathrm{L}$ of $10 \%$ SDS, and $9 \mu \mathrm{L}$ of proteinase $\mathrm{K}(20 \mathrm{mg} / \mathrm{mL}))$. RNA was purified using TRIzol followed by RT-qPCR analysis.

For the formaldehyde crosslinking RIP assay, 1\% formaldehyde was used to fix the cells for $10 \mathrm{~min}$ at RT. The crosslinking was quenched by the addition of glycine to a final concentration of $0.14 \mathrm{M}$, and the cells were incubated at RT for $30 \mathrm{~min}$. After centrifuging at $1200 \mathrm{rpm}$ for $5 \mathrm{~min}$, the cell pellet was lysed with
$600 \mu \mathrm{L}$ RIP buffer, followed by sonication (power 10 for four cycles, $10 \mathrm{~s}$ for sonication and $50 \mathrm{~s}$ for rest). After centrifuging at 12,000 rpm for $15 \mathrm{~min}$, the supernatant was pre-cleared with $10 \mu \mathrm{L}$ Dynabeads Protein $\mathrm{G}$. The sample were then incubated with $3 \mu \mathrm{g}$ of anti-NPM1 antibody (ab10530, abcam) for $2 \mathrm{~h}$ at $4{ }^{\circ} \mathrm{C}$, and $20 \mu \mathrm{L}$ Dynabeads Protein-G were added to the mixture and incubated overnight at $4{ }^{\circ} \mathrm{C}$ on a rotating shaker. Next, the antibody-bead slurry was washed four times at $4{ }^{\circ} \mathrm{C}$ with wash buffer I $(50 \mathrm{mM}$ Tris, $\mathrm{pH} 7.4,500 \mathrm{mM} \mathrm{NaCl}, 1 \% \mathrm{NP}-40,0.5 \%$ sodium deoxycholate, $0.5 \mathrm{mM}$ PMSF, $2 \mathrm{mM}$ RVC, protease inhibitor cocktail (Roche, 4693124001)), and wash buffer II (50 mM Tris, pH 7.4, $500 \mathrm{mM}$ $\mathrm{NaCl}, 1 \% \mathrm{NP}-40,0.5 \%$ sodium deoxycholate, $1 \mathrm{M}$ Urea, $0.5 \mathrm{mM}$ PMSF, 2 mM RVC, protease inhibitor cocktail (Roche, 4693124001)), respectively. Reverse crosslinking was performed by adding $8 \mu \mathrm{L}$ $5 \mathrm{M} \mathrm{NaCl}$, followed by addition of $2 \mu \mathrm{L}$ proteinase $\mathrm{K}(20 \mathrm{mg} / \mathrm{mL})$ at $55^{\circ} \mathrm{C}$ for $2 \mathrm{~h}$. RNA was purified using TRlzol followed by RT-qPCR analysis.

\section{Biotin-labeled RNA pull-down assay}

The LETN RNA truncations were labeled with biotin-16-UTP by in vitro transcription with SP6 polymerase and DIG RNA labeling Mix (11685597910, Roche) according to the manufacturers' instructions. The biotin-labeled RNA was captured with Dynabeads MyOne Streptavidin C1 (65002, invitrogen) according to the recommended protocol. Five million $\mathrm{HUH7}$ cells were harvested and lysed with lysis buffer (50 mM Tris, pH 7.4, $150 \mathrm{mM} \mathrm{NaCl}, 0.5 \%$ NP-40, $0.5 \mathrm{mM}$ PMSF, $2 \mathrm{mM}$ RVC, protease inhibitor cocktail (Roche)) followed by sonication (power 10 for four cycles, $10 \mathrm{~s}$ for sonication and $50 \mathrm{~s}$ for rest). This mixture was then added into the cell lysate, followed by incubation for $4 \mathrm{~h}$ at $4{ }^{\circ} \mathrm{C}$. After washing for four times with wash buffer $(50 \mathrm{mM}$ Tris, $\mathrm{pH} 7.4,300 \mathrm{mM} \mathrm{NaCl}$, $0.5 \% \mathrm{NP}-40,0.5 \mathrm{mM}$ PMSF, $2 \mathrm{mM}$ RVC, protease inhibitor cocktail (Roche)) at $4{ }^{\circ} \mathrm{C}, 5 \mathrm{~min}$ each, the complex was boiled for $10 \mathrm{~min}$ at $100^{\circ} \mathrm{C}$ in $1 \times$ SDS loading buffer and the protein pulled down was analyzed by western blotting.

\section{In vitro RNA-protein Interaction assay}

The LETN RNA fragment was transcribed in vitro with SP6 polymerase and labeled with biotin-16-UTP. The LETN fragment was incubated with purified NPM1 or the mutant proteins in the binding buffer (50 mM Tris, pH 7.4, $150 \mathrm{mM} \mathrm{NaCl}, 0.5 \%$ NP-40, 0.5 mM PMSF, 2 mM RVC and protease inhibitor cocktail (Roche)) for $2 \mathrm{~h}$ at $4^{\circ} \mathrm{C}$. Meanwhile, Dynabeads Protein-G were incubated with $3 \mu \mathrm{g}$ of anti-NPM1 antibody (ab52644, abcam) for $2 \mathrm{~h}$ at $4{ }^{\circ} \mathrm{C}$. The sample in the binding buffer was added to the antibody-bead slurry and incubated overnight at $4{ }^{\circ} \mathrm{C}$ on a rotating platform. Next, the mixtures were washed with wash buffer $(50 \mathrm{mM}$ Tris, $\mathrm{pH} 7.4$, $300 \mathrm{mM} \mathrm{NaCl}, 0.5 \%$ NP-40, $0.5 \mathrm{mM}$ PMSF, $2 \mathrm{mM} \mathrm{RVC}$, protease inhibitor cocktail (Roche)) for five times at $4{ }^{\circ} \mathrm{C}$. An aliquot of the sample was transferred to a new microcentrifuge tube and kept as quality control via western blotting. The RNA-protein complex was resuspended with proteinase $\mathrm{K}$ buffer $(117 \mu \mathrm{L}$ of wash buffer, 15 $\mu \mathrm{L}$ of $10 \% \mathrm{SDS}$, and $9 \mu \mathrm{L}$ of proteinase $\mathrm{K}(20 \mathrm{mg} / \mathrm{mL}))$. RNA was purified using TRIzol followed by RT-qPCR analysis.

Chromatin immunoprecipitation

HUH7 cells (10 million) were harvested and fixed with $1 \%$ formaldehyde in $10 \mathrm{~mL}$ PBS for $10 \mathrm{~min}$ at $37^{\circ} \mathrm{C}$. The crosslinking was quenched by the addition of glycine to a final concentration of $0.14 \mathrm{M}$, and the cells were incubated at RT for $30 \mathrm{~min}$. The cell pellet was lysed with $600 \mu \mathrm{L}$ lysis buffer $(50 \mathrm{mM}$ Tris, pH 7.4, $150 \mathrm{mM} \mathrm{NaCl}, 0.5 \%$ NP-40, $0.5 \mathrm{mM}$ PMSF, $2 \mathrm{mM} \mathrm{RVC}$, protease inhibitor cocktail (Roche)) at $4^{\circ} \mathrm{C}$ for $30 \mathrm{~min}$. The cell lysate was sonicated to achieve 300-700 bp DNA fragments. The lysate was cleared by centrifuging at $12,000 \times g$ for $10 \mathrm{~min}$ at $4{ }^{\circ} \mathrm{C}$. An aliquot of the sheared chromatin was transferred to a new microcentrifuge tube and kept as a reference of input DNA. The remaining sample was mixed with Dynabeads at $4{ }^{\circ} \mathrm{C}$ for $2 \mathrm{~h}$ to eliminate 
non-specific binding. Meanwhile the beads were incubated for $2 \mathrm{~h}$ at $4{ }^{\circ} \mathrm{C}$ with $4 \mu \mathrm{g}$ anti-NPM1 antibody or anti-lgG antibody and washed three times with PBS/BSA. Then the sample was added to antibody-bead slurry and incubated overnight at $4{ }^{\circ} \mathrm{C}$ on a rotating platform. Next, the slurry was washed five times with RIPA buffer (50 mM Hepes, pH 8.0, 1\% NP-40, 0.7\% DOC, $0.5 \mathrm{M} \mathrm{LiCl}, 1 \times$ protease inhibitor cocktail). The complex was eluted by adding $100 \mu \mathrm{L}$ fresh-prepared elution buffer (10 mM Tris, $\mathrm{pH}$ 8.0, $1 \mathrm{mM}$ EDTA, and $1 \%$ SDS) with rotation at RT for $15 \mathrm{~min}$. Reverse crosslinking was performed at $65^{\circ} \mathrm{C}$ overnight by adding $8 \mu \mathrm{L}$ $5 \mathrm{M} \mathrm{NaCl}$, followed by supplemented with $2 \mu \mathrm{L}$ proteinase $\mathrm{K}$ $(20 \mathrm{mg} / \mathrm{mL})$ at $55^{\circ} \mathrm{C}$ for $2 \mathrm{~h}$. Genomic DNA was isolated using a Tiangen DNA purification kit and then incubated with $1 \mu \mathrm{L}$ of RNase $(20 \mathrm{mg} / \mathrm{mL})$ at $37^{\circ} \mathrm{C}$ for $1 \mathrm{~h}$. Finally, the DNA was re-isolated using AMpure XP beads.

\section{Co-immunoprecipitation}

The cells were harvested and lysed with Pierce IP lysis buffer (87787, Thermo) supplemented with $1 \mathrm{mM}$ PMSF and protease inhibitor cocktail (Roche) followed by sonication (power 10 for four cycles, $10 \mathrm{~s}$ for sonication and $50 \mathrm{~s}$ for rest). One tenth of the lysate was taken out for a reference of input. Meanwhile the Dynabeads Protein- $G$ were incubated for $2 \mathrm{~h}$ at $4{ }^{\circ} \mathrm{C}$ with $4 \mu \mathrm{g}$ antiNPM1 antibody or anti-lgG antibody and washed three times with PBS/BSA. The remaining lysate was then incubated with antiNPM1-Dynabeads Protein-G slurry and incubated overnight at $4{ }^{\circ} \mathrm{C}$ on a rotating platform. Next, the beads were washed for four times with wash buffer (50 mM Tris, $\mathrm{pH} 7.4,300 \mathrm{mM} \mathrm{NaCl}, 0.5 \%$ NP-40, $0.5 \mathrm{mM}$ PMSF, $2 \mathrm{mM}$ RVC, protease inhibitor cocktail (Roche)) at $4{ }^{\circ} \mathrm{C}$. After discarding the supernatant, the beads were resuspended with $40 \mu \mathrm{L} 1 \times \mathrm{SDS}$ loading buffer and heated at $100^{\circ} \mathrm{C}$ for $10 \mathrm{~min}$, followed by western blot analysis.

\section{In vitro NPM1 oligomerization assay}

Purified NPM1 in the binding buffer (50 mM Tris, pH 7.4, $150 \mathrm{mM}$ $\mathrm{NaCl}, 0.5 \% \mathrm{NP}-40,0.5 \mathrm{mM}$ PMSF) was subjected to sonication (ten cycles, $5 \mathrm{~s}$ for sonication and $15 \mathrm{~s}$ for rest). The $5^{\prime}$ fragment of LETN was synthesized by in vitro transcription, which is around $2000 \mathrm{nt}$. The protein-RNA binding was carried out at RT for $30 \mathrm{~min}$, with indicated concentrations of the protein and the RNA in the binding buffer supplemented with $2 \mathrm{mM}$ RVC and protease inhibitor cocktail (Roche). The products were immediately loaded into a $10 \%$ native PAGE gels without SDS followed by western blotting analysis.

Transmission electron microscopy

Huh7 cells were fixed with $2.5 \%$ glutaraldehyde and $2.0 \%$ paraformaldehyde buffer with pH 7.2. The cells were then kept at $4{ }^{\circ} \mathrm{C}$ overnight. Next, the cells were washed with PB $(0.1 \mathrm{M}, \mathrm{pH}$ 7.2) buffer for three times, and treated with $1.5 \% \mathrm{~K}_{3} \mathrm{Fe}(\mathrm{CN})_{6}+1 \%$ $\mathrm{OsO}_{4}$ buffer and kept at $4{ }^{\circ} \mathrm{C}$ for $1 \mathrm{~h}$. The cells were washed with PB $(0.1 \mathrm{M}, \mathrm{pH} 7.2)$ buffer and $\mathrm{ddH}_{2} \mathrm{O}$ for three times ( 10 min each wash), and then treated with $1 \%$ uranyl acetate and kept at RT for $1 \mathrm{~h}$. Cells were treated in turn by dehydrated in ethanol $(30 \%, 50 \%$, $70 \%, 90 \%$, and $100 \% ; 10 \mathrm{~min}$ each), $100 \%$ epoxy propane twice, $\mathrm{PO}$ and 812 resin $(1: 2 ; 2: 1)$ for $30 \mathrm{~min}$ at $\mathrm{RT}$, and resin alone overnight. The sample was embedded and made into ultrathin sections. Images were obtained with a H-7650B TEM at $80 \mathrm{kV}$.

Neural differentiation from human ESCs

Human ES cell line H9 (WA09 line, NIH registry 0046) was maintained on Matrigel (Corning \#354277)-coated dishes with the E8 medium (Thermo \#A1517001) and detached with $500 \mu \mathrm{M}$ EDTA (Thermo \#15575020, diluted as 1:1000 with PBS before use) for passage. Neural induction was performed majorly according to the published method. Briefly, before neural induction, human ESCs were dissociated into single cells with TrypLE (Thermo \#12605028) and plated in Matrigel-coated 12-well plate at the density of 70,000 cells/well in E8 medium supplied with $10 \mu \mathrm{M}$ Y27632 (Selleck \#S1049). Once the cells reached 95\% confluence, initiate neural induction by changing the medium to neural induction medium containing DMEM/F12 (Sigma \#D6421), Neurobasal medium (Thermo \#21103049) at 1:1, $2 \mathrm{mM}$ L-glutamine (Thermo \#A2916801), 1× glutaMAX (Thermo \#35050061), 0.5× NEAA (Thermo \#11140050), 0.5× N2 (Thermo \#17502048), 0.5× B27 (Thermo \#17504044), $5 \mu \mathrm{g} / \mathrm{mL}$ insulin (Sigma \#19278) and $100 \mu \mathrm{M}$ 2-Mercaptoethanol (Thermo \#21985023). $1 \mu \mathrm{M}$ Dorsomorphin (Selleck \#S7840) and $10 \mu \mathrm{M}$ SB431542 (Selleck \#S1067) were supplied into neural induction medium freshly. The human ESCs were cultured in this medium for 14 days and showed neural epithelial cell morphology. Then the cells were dissociated with Accutase (STEMCELL Tech. \#07920) and split 1:3 in poly-L-ornithine (Sigma \#4957) and Laminin (Sigma \#L2020)-coated 12-well plate in neural induction medium supplied with $20 \mathrm{ng} / \mathrm{mL}$ bFGF (Thermo \#PHG0021L) for another 8 days. After that, the induced NPCs were dissociated with Accutase and split 1:3 and cultured in poly-Lornithine and Laminin-coated 12-well plate in neural progenitor medium containing $1 \mathrm{mM}$ sodium pyruvate (Thermo \#11360070), $2 \mathrm{mM}$ L-glutamine, $1 \mathrm{mM} \mathrm{N}$-acetyl-cysteine (Sigma \#A9165), 1× N2, $1 \times \mathrm{B} 27,10 \mathrm{ng} / \mathrm{mL} \mathrm{bFGF}$ and $10 \mathrm{ng} / \mathrm{mL}$ EGF.

Lentiviral infection and immunofluorescence of induced NPCs Two days after plating, the induced NPCs were affected with lentivirus carrying mock sequence and coding sequence of shRNA against $L E T N$. Four days after infection, the NPC cultures were fixed with $4 \%$ polyformaldehyde. Then the cells were blocked with blocking buffer (5\% BSA, Triton X-100 in PBS), and incubated with anti-Ki67 antibody (Thermo \#PA5-19462) 1:500 and Alexa Fluor 488-conjugated antibodies (Thermo \#R37116). The nucleus was counterstained with DAPI.

Overall survival analysis

After allocating the patients into different groups, Kaplan-Meier survival curves were prepared for each of the patient groups. The clinical data were downloaded from the TCGA data portal. The R package 'survival' was used for comparison of the patient survival rates among different subgroups. The statistical significance of the prognosis difference was inferred with the log-rank test.

\section{Statistical analysis}

Pair-wise comparisons of the experimental data were done with GraphPad Prism 6 or Excel, and the statistical analysis was performed with Student's $t$-test unless indicated as other methods. Unless specified on the figure, all the statistical analyses were done between the experimental condition and the control (marked as siNC, shNC, EV, sgEV, or ASO-NC for the gene perturbation studies, IgG or anti-GFP for the RIP assays). The significance levels were marked by NS (not significant), ${ }^{*}(P$-value $<$ $0.05),{ }^{* *}(P$-value $<0.01)$, and ${ }^{* * *}(P$-value $<0.001)$. The error bars on the figures represent standard deviation (SD) of at least three biological replicates.

\section{DATA AVAILABILITY}

The gene expression datasets generated in this study are available in the GEO database repository (GEO accession ID: GSE140708).

\section{ACKNOWLEDGEMENTS}

The authors would like to thank the supports from the Tsinghua University Branch of China National Center for Protein Sciences (Beijing) and Tsinghua University Technology Center for Protein Research, including the core facilities of Genome Sequencing and Analysis, Biocomputing, Cell Imaging, Protein Preparation and Identification, Cell Function Analyzing, and Protein Chemistry and Proteomics, and the Lab Animal Center at Tsinghua University. This work was supported by the National Key R\&D Program, Precision Medicine Project (2016YFC0906001), the Tsinghua University Spring Breeze Fund (2020Z99CFZ022), the National Natural 
Science Foundation of China (81972912, 31671381, and 91540109), and the Tsinghua University Initiative Scientific Research Program (2019Z06QCX01). We thank Dr. Xian Cao, Dr. Haitao Li, Dr. Hang Shi, Dr. Pilong Li, and the members of the Yang laboratory for the discussions and comments during preparation of the manuscript.

\section{AUTHOR CONTRIBUTIONS}

$X . W$. and X.Y. conceived and designed the experiments. X.W. conducted all the experiments except the assays with human ESC and NPC, with help from F.Z., Y.C., J.F., and X.L. X.H. performed most of the high-throughput data analyses with help from R.H. and Y.L. W.S. performed the CNV data analysis. H.X. and Z.X. performed the IncRNA functional survey. H.Z. helped analyze the clinical data. Q.B. and Q.S. performed the assays with human ESC and NPC. X.Y. supervised the whole project. X.W. and X.Y. wrote the manuscript with inputs from all other authors.

\section{ADDITIONAL INFORMATION}

Supplementary information accompanies this paper at https://doi.org/10.1038/ s41422-020-00458-6.

Competing interests: The authors declare no competing interests.

\section{REFERENCES}

1. Derrien, T. et al. The GENCODE v7 catalog of human long noncoding RNAs: analysis of their gene structure, evolution, and expression. Genome Res. 22, 1775-1789 (2012)

2. Fang, S. et al. NONCODEV5: a comprehensive annotation database for long noncoding RNAs. Nucleic Acids Res. 46, D308-D314 (2018).

3. Volders, P. -J. et al. LNCipedia 5: towards a reference set of human long noncoding RNAs. Nucleic Acids Res. 47, D135-D139 (2019).

4. Djebali, S. et al. Landscape of transcription in human cells. Nature 489, 101-108 (2012).

5. Quinn, J. J. \& Chang, H. Y. Unique features of long non-coding RNA biogenesis and function. Nat. Rev. Genet. 17, 47-62 (2016).

6. Kopp, F. \& Mendell, J. T. Functional classification and experimental dissection of long noncoding RNAs. Cell 172, 393-407 (2018).

7. Fernandes, J. C. R., Acuna, S. M., Aoki, J. I., Floeter-Winter, L. M. \& Muxel, S. M. Long non-coding RNAs in the regulation of gene expression: physiology and disease. Noncoding RNA 5, 17 (2019).

8. Gao, Y. et al. Lnc2Cancer v2.0: updated database of experimentally supported long non-coding RNAs in human cancers. Nucleic Acids Res. 47, D1028-D1033 (2019).

9. Schmitt, A. M. \& Chang, H. Y. Long noncoding RNAs in cancer pathways. Cancer Cell 29, 452-463 (2016).

10. Tang, Y. et al. The regulatory role of long noncoding RNAs in cancer. Cancer Lett. 391, 12-19 (2017).

11. Boisvert, F. M., van Koningsbruggen, S., Navascues, J. \& Lamond, A. I. The multifunctional nucleolus. Nat. Rev. Mol. Cell Biol. 8, 574-585 (2007).

12. Montanaro, L., Trere, D. \& Derenzini, M. Nucleolus, ribosomes, and cancer. Am. J. Pathol. 173, 301-310 (2008)

13. Tsai, R. Y. \& Pederson, T. Connecting the nucleolus to the cell cycle and human disease. FASEB J. 28, 3290-3296 (2014).

14. Zhao, Z., Senturk, N., Song, C. \& Grummt, I. IncRNA PAPAS tethered to the rDNA enhancer recruits hypophosphorylated CHD4/NuRD to repress rRNA synthesis at elevated temperatures. Genes Dev. 32, 836-848 (2018).

15. Bierhoff, $\mathrm{H}$. et al. Quiescence-induced LncRNAs trigger H4K20 trimethylation and transcriptional silencing. Mol. Cell 54, 675-682 (2014).

16. Xing, Y. - H. et al. SLERT regulates DDX21 rings associated with Pol I transcription. Cell 169, 664-678 (2017).

17. Papaioannou, D. et al. The long non-coding RNA HOXB-AS3 regulates ribosomal RNA transcription in NPM1-mutated acute myeloid leukemia. Nat. Commun. 10, 5351 (2019).

18. Box, J. K. et al. Nucleophosmin: from structure and function to disease development. BMC Mol. Biol. 17, 19 (2016).

19. Murano, K., Okuwaki, M., Hisaoka, M. \& Nagata, K. Transcription regulation of the rRNA gene by a multifunctional nucleolar protein, B23/nucleophosmin, through its histone chaperone activity. Mol. Cell. Biol. 28, 3114-3126 (2008).

20. Mitrea, D. M. et al. Nucleophosmin integrates within the nucleolus via multimodal interactions with proteins displaying R-rich linear motifs and rRNA. Elife 5, e13571 (2016).

21. Mitrea, D. M. et al. Self-interaction of NPM1 modulates multiple mechanisms of liquid-liquid phase separation. Nat. Commun. 9, 842 (2018).

22. Feric, M. et al. Coexisting liquid phases underlie nucleolar subcompartments. Cell 165, 1686-1697 (2016).
23. Holmberg Olausson, K., Nister, M. \& Lindstrom, M. S. Loss of nucleolar histone chaperone NPM1 triggers rearrangement of heterochromatin and synergizes with a deficiency in DNA methyltransferase DNMT3A to drive ribosomal DNA transcription. J. Biol. Chem. 289, 34601-34619 (2014).

24. Liu, G., Chen, X. \& Leffak, M. Oligodeoxynucleotide binding to (CTG) · (CAG) microsatellite repeats inhibits replication fork stalling, hairpin formation, and genome instability. Mol. Cell. Biol. 33, 571-581 (2013).

25. Hanley, M. L., Yoo, T. Y., Sonnett, M., Needleman, D. J. \& Mitchison, T. J. Chromosomal passenger complex hydrodynamics suggests chaperoning of the inactive state by nucleoplasmin/nucleophosmin. Mol. Biol. Cell 28, 1444-1456 (2017).

26. Okuwaki, M. et al. Function of homo- and hetero-oligomers of human nucleoplasmin/nucleophosmin family proteins NPM1, NPM2 and NPM3 during sperm chromatin remodeling. Nucleic Acids Res. 40, 4861-4878 (2012).

27. Lindstrom, M. S. NPM1/B23: a multifunctional chaperone in ribosome biogenesis and chromatin remodeling. Biochem. Res. Int. 2011, 195209 (2011).

28. $\mathrm{Yu}, \mathrm{Y}$. et al. Nucleophosmin is essential for ribosomal protein L5 nuclear export. Mol. Cell. Biol. 26, 3798-3809 (2006).

29. Grisendi, S. et al. Role of nucleophosmin in embryonic development and tumorigenesis. Nature 437, 147-153 (2005).

30. Lin, J., Kato, M., Nagata, K. \& Okuwaki, M. Efficient DNA binding of NF-kappaB requires the chaperone-like function of NPM1. Nucleic Acids Res. 45, 3707-3723 (2017).

31. Grisendi, S., Mecucci, C., Falini, B. \& Pandolfi, P. P. Nucleophosmin and cancer. Nat. Rev. Cancer 6, 493-505 (2006).

32. Sarropoulos, I., Marin, R., Cardoso-Moreira, M. \& Kaessmann, H. Developmental dynamics of IncRNAs across mammalian organs and species. Nature 571, 510-514 (2019)

33. Prinos, P., Lacoste, M. -C., Wong, J., Bonneau, A. -M. \& Georges, E. Mutation of cysteine 21 inhibits nucleophosmin/B23 oligomerization and chaperone activity. Int. J. Biochem. Mol. Biol. 2, 24-30 (2011).

34. Dutta, S. et al. The crystal structure of nucleoplasmin-core: implications for histone binding and nucleosome assembly. Mol. Cell 8, 841-853 (2001).

35. Savkur, R. S. \& Olson, M. O. Preferential cleavage in pre-ribosomal RNA byprotein B23 endoribonuclease. Nucleic Acids Res. 26, 4508-4515 (1998).

36. Swaminathan, V., Kishore, A. H., Febitha, K. K. \& Kundu, T. K. Human histone chaperone nucleophosmin enhances acetylation-dependent chromatin transcription. Mol. Cell. Biol. 25, 7534-7545 (2005).

37. Huang, N., Negi, S., Szebeni, A. \& Olson, M. O. J. Protein NPM3 interacts with the multifunctional nucleolar protein B23/nucleophosmin and inhibits ribosome biogenesis. J. Biol. Chem. 280, 5496-5502 (2005).

38. Schon, M. A., Kellner, M. J., Plotnikova, A., Hofmann, F. \& Nodine, M. D. NanoPARE: parallel analysis of RNA 5' ends from low-input RNA. Genome Res. 28, 1931-1942 (2018).

39. Cheng, C. et al. Understanding transcriptional regulation by integrative analysis of transcription factor binding data. Genome Res. 22, 1658-1667 (2012).

40. Yuan, J. H. et al. A long noncoding RNA activated by TGF-beta promotes the invasion-metastasis cascade in hepatocellular carcinoma. Cancer Cell 25, 666-681 (2014).

41. Spector, D. L., Ochs, R. L. \& Busch, H. Silver staining, immunofluorescence, and immunoelectron microscopic localization of nucleolar phosphoproteins B23 and C23. Chromosoma 90, 139-148 (1984).

42. Yung, B. Y. -M., Hui, E. K. -W. \& Chan, P. -K. Protein B23 (M.W./pl = 37 kD/5.1) is the only major protein extracted from HeLa nucleoli with $3 \mathrm{M}$ urea. Life Sci. 51, 915-920 (1992).

43. Cerqueira, A. V. \& Lemos, B. Ribosomal DNA and the nucleolus as keystones of nuclear architecture, organization, and function. Trends Genet. 35, 710-723 (2019).

44. Mitrea, D. M. et al. Structural polymorphism in the N-terminal oligomerization domain of NPM1. Proc. Natl Acad. Sci. USA 111, 4466-4471 (2014).

45. Iarovaia, O. V. et al. Nucleolus: a central Hub for nuclear functions. Trends Cell Biol. 29, 647-659 (2019).

46. Maiser, A. et al. Super-resolution in situ analysis of active ribosomal DNA chromatin organization in the nucleolus. Sci. Rep. 10, 7462 (2020).

47. Bersaglieri, C. \& Santoro, R. Genome organization in and around the nucleolus. Cells 8, 579 (2019).

48. Yao, R. W. et al. Nascent Pre-rRNA sorting via phase separation drives the assembly of dense fibrillar components in the human nucleolus. Mol. Cell 76, 767-783 (2019)

49. Frehlick, L. J., Eirin-Lopez, J. M. \& Ausio, J. New insights into the nucleophosmin/ nucleoplasmin family of nuclear chaperones. Bioessays 29, 49-59 (2007).

50. Holmberg Olausson, K., Elsir, T., Moazemi Goudarzi, K., Nister, M. \& Lindstrom, M. $\mathrm{S}$. NPM1 histone chaperone is upregulated in glioblastoma to promote cell survival and maintain nucleolar shape. Sci. Rep. 5, 16495 (2015). 
51. Okuwaki, M., Kato, K., Shimahara, H., Tate, S. \& Nagata, K. Assembly and disassembly of nucleosome core particles containing histone variants by human nucleosome assembly protein I. Mol. Cell. Biol. 25, 10639-10651 (2005).

52. Namboodiri, V. M., Akey, I. V., Schmidt-Zachmann, M. S., Head, J. F. \& Akey, C. W. The structure and function of Xenopus NO38-core, a histone chaperone in the nucleolus. Structure 12, 2149-2160 (2004).

53. Okuwaki, M., Matsumoto, K., Tsujimoto, M. \& Nagata, K. Function of nucleophosmin/ B23, a nucleolar acidic protein, as a histone chaperone. FEBS Lett. 506, 272-276 (2001).

54. Hingorani, K., Szebeni, A. \& Olson, M. O. Mapping the functional domains of nucleolar protein B23. J. Biol. Chem. 275, 24451-24457 (2000).

55. Anselm, E., Thomae, A. W., Jeyaprakash, A. A. \& Heun, P. Oligomerization of drosophila nucleoplasmin-like protein is required for its centromere localization. Nucleic Acids Res. 46, 11274-11286. (2018)

56. Lin, J., Hisaoka, M., Nagata, K. \& Okuwaki, M. Functional characterization and efficient detection of nucleophosmin/NPM1 oligomers. Biochem. Biophys. Res. Commun. 480, 702-708 (2016).

57. Vascotto, C. et al. APE1/Ref-1 interacts with NPM1 within nucleoli and plays a role in the rRNA quality control process. Mol. Cell. Biol. 29, 1834-1854 (2009).

58. Balusu, R. et al. Targeting levels or oligomerization of nucleophosmin 1 induces differentiation and loss of survival of human AML cells with mutant NPM1. Blood 118, 3096-3106 (2011).

59. Yung, B. Y. -M., Busch, H. \& Chan, P. -K. Translocation of nucleolar phosphoprotein B23 (37kDapl 5.1) induced by selective inhibitors of ribosome synthesis. Biochim. Biophys. Acta 826, 167-173 (1985).

60. Sirri, V., Urcuqui-Inchima, S., Roussel, P. \& Hernandez-Verdun, D. Nucleolus: the fascinating nuclear body. Histochem. Cell Biol. 129, 13-31 (2008).

61. Schofer, C. \& Weipoltshammer, K. Nucleolus and chromatin. Histochem. Cell Biol. 150, 209-225 (2018).

62. Liu, Q. -R. \& Chan, P. K. Formation of nucleophosmin/B23 oligomers requires both the amino-and the carboxyl-terminal domains of the protein. Eur. J. Biochem. 200, 715-721 (1991)

63. Chiarella, S. et al. Nucleophosmin mutations alter its nucleolar localization by impairing G-quadruplex binding at ribosomal DNA. Nucleic Acids Res. 41, 3228-3239 (2013).

64. Bergstralh, D. T. et al. Global functional analysis of nucleophosmin in Taxol response, cancer, chromatin regulation, and ribosomal DNA transcription. Exp. Cell Res. 313, 65-76 (2007).

65. Tau, G. Z. \& Peterson, B. S. Normal development of brain circuits. Neuropsychopharmacology 35, 147-168 (2010).

66. Chen, T. et al. ADAR1 is required for differentiation and neural induction by regulating microRNA processing in a catalytically independent manner. Cell Res. 25, 459-476 (2015)

67. Adriaens, C. \& Marine, J. C. NEAT1-containing paraspeckles: Central hubs in stress response and tumor formation. Cell Cycle 16, 137-138 (2017).

68. Wang, L. et al. CPAT: Coding-Potential Assessment Tool using an alignment-free logistic regression model. Nucleic Acids Res. 41, e74 (2013).

69. Zou, Q. et al. Survey of the translation shifts in hepatocellular carcinoma with ribosome profiling. Theranostics 9, 4141-4155 (2019).

70. Shin, Y. \& Brangwynne, C. P. Liquid phase condensation in cell physiology and disease. Science 357, eaaf4382 (2017)

71. Mangan, H., Gailin, M. O. \& McStay, B. Integrating the genomic architecture of human nucleolar organizer regions with the biophysical properties of nucleoli. FEBS J. 284, 3977-3985 (2017).
72. Frottin, F. et al. The nucleolus functions as a phase-separated protein quality control compartment. Science 365, 342-347 (2019).

73. Derenzini, M. et al. Nucleolar size indicates the rapidity of cell proliferation in cancer tissues. J. Pathol. 191, 181-186 (2000).

74. Scheer, U. \& Hock, R. Structure and function of the nucleolus. Curr. Opin. Cell Biol. 11, 385-390 (1999).

75. Lebelo, S. L. \& van der Horst, G. The ultrastructure of the Sertoli cell of the vervet monkey, Chlorocebus aethiops. Tissue Cell 42, 348-354 (2010).

76. Weeks, S. E., Metge, B. J. \& Samant, R. S. The nucleolus: a central response hub for the stressors that drive cancer progression. Cell. Mol. Life Sci. 76, 4511-4524 (2019).

77. Genoveso, M. J. et al. Formation of adenovirus DNA replication compartments and viral DNA accumulation sites by host chromatin regulatory proteins including NPM1. FEBS J. 287, 205-217 (2020).

78. Liu, Q. et al. LncRNA SAMD12-AS1 promotes cell proliferation and inhibits apoptosis by interacting with NPM1. Sci. Rep. 9, 11593 (2019).

79. Wang, K. et al. Genome-wide identification of post-translational modulators of transcription factor activity in human B cells. Nat. Biotechnol. 27, 829-839 (2009).

80. Liu, Y. et al. Dependency of the cancer-specific transcriptional regulation circuitry on the promoter DNA methylome. Cell Rep. 26, 3461-3474 (2019).

81. $\mathrm{Li}, \mathrm{X}$. et al. Oncogenic properties of NEAT1 in prostate cancer cells depend on the CDC5L-AGRN transcriptional regulation circuit. Cancer Res. 78, 4138-4149 (2018).

82. Goldman, M. et al. The UCSC Xena platform for public and private cancer genomics data visualization and interpretation. bioRxiv https://doi.org/10.1101/ 326470 (2019).

83. Mermel, C. H. et al. GISTIC2.0 facilitates sensitive and confident localization of the targets of focal somatic copy-number alteration in human cancers. Genome Biol. 12, R41-R41 (2011)

84. Liu, Y. et al. Insights from multidimensional analyses of the pan-cancer DNA methylome heterogeneity and the uncanonical CpG-gene associations. Int. J. Cancer 143, 2814-2827 (2018).

85. Hacot, S. et al. Isolation of nucleoli. Curr. Protoc. Cell Biol. https://doi.org/10.1002/ 0471143030.cb0336s47 (2010)

86. Wu, Y. et al. Function of HNRNPC in breast cancer cells by controlling the dsRNAinduced interferon response. EMBO J. 37, e99017 (2018).

87. Holoubek, A. et al. Monitoring of nucleophosmin oligomerization in live cells. Methods Appl. Fluoresc. 6, 035016 (2018).

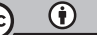

Open Access This article is licensed under a Creative Commons Attribution 4.0 International License, which permits use, sharing, adaptation, distribution and reproduction in any medium or format, as long as you give appropriate credit to the original author(s) and the source, provide a link to the Creative Commons license, and indicate if changes were made. The images or other third party material in this article are included in the article's Creative Commons license, unless indicated otherwise in a credit line to the material. If material is not included in the article's Creative Commons license and your intended use is not permitted by statutory regulation or exceeds the permitted use, you will need to obtain permission directly from the copyright holder. To view a copy of this license, visit http://creativecommons. org/licenses/by/4.0/.

(c) The Author(s) 2021 